REVISTA DE DERECHO UNED, NÚM. 23, 2018

\title{
TECNOCIENCIA Y DERECHO. ANÁLISIS DE LA REGULACIÓN PENAL DEL CONTROL DE RIESGOS
}

\author{
TECHNOSCIENCE AND LAW. \\ ANALYSIS OF THE CRIMINAL REGULATION OF RISK CONTROL \\ Premio de Artículos Jurídicos "García Goyena» \\ XVII Edición \\ Primer accésit \\ Mariana Noelia Solari Merlo \\ Pseudónimo: Perséfone
}

Rsumen: Uno de los problemas fundamentales a los que se enfrentan las sociedades actuales es el relativo al control de los riesgos que su propio funcionamiento genera. La expansión de las actividades tecnocientíficas a cada resquicio de la vida del ser humano no sólo conlleva bienestar y progreso sino también peligros inherentes a su utilización.

Desde la incorporación del principio administrativo de precaución al Derecho penal, el legislador nacional ha seguido un modelo de regulación que ha venido transformando y ampliando los límites al ius puniendi, adelantando las barreras punitivas mediante la proliferación de leyes penales en blanco, delitos de peligro y el castigo de la imprudencia. La última reforma de 2015 no viene sino a incidir en esta metodología.

Este adelantamiento no sólo colisiona con los principios liberales; sirve también para evitar pronunciarse sobre cuestiones más complejas como pueden ser las relativas a la determinación de la causalidad entre algunas actividades científicas y su resultado lesivo. 
En el presente trabajo se analizarán estas cuestiones y se ofrecerán las soluciones que se estiman más adecuadas partiendo de una reconsideración del papel que el Derecho - penal- está llamado a desempeñar en la sociedad y dotándolo de su autonomía perdida.

Palabras clave: Derecho penal del riesgo, tecnociencia, principio de precaución, causalidad, interpretación.

Abstract: One of the fundamental problems faced by current societies is the control of the risks that their own operation generates. The expansion of techno-scientific activities to every corner of human life not only entails well-being and progress but also inherent dangers in their use.

Since the incorporation of the administrative precautionary principle into criminal law, the national legislator has followed a regulatory model that has been transforming and extending the limits to ius puniendi, advancing punitive barriers through the proliferation of blank criminal laws, crimes of danger and the punishment of imprudence. The latest reform of 2015 falls on this methodology.

This advance not only collides with liberal principles; it also allows to avoid pronouncing about more complex issues such as those related to the determination of causality between some scientific activities and their harmful outcome.

In the present work these issues will be analyzed and the most appropriate solutions will be offered starting from a reconsideration of the role that the Law - criminal - is called to perform in society and giving it its lost autonomy.

Keywords: Criminal law of risk, technoscience, precautionary principle, causality, interpretation.

Sumario: I. La sociedad actual bajo el paradigma de la tecnociencia.-II. Colisión intercientífica: consecuencias de la dispar naturaleza de la actividad tecnocientífica y la jurídica.-III. Problemas asociados a la intervención estatal en el control de riesgos.-IV. Fundamentos del control penal del riesgo.- -V. El modelo de tipificación penal de la actividad científica: el trinomio de la ley penal en blanco, los delitos de peligro y el castigo de la imprudencia. V.1. Ciencia y remisiones legislativas. V.2. Ciencia como sinónimo de peligro. V.3. La ciencia y la imprudencia.-VI. Problemas estructurales del modelo de tipificación adoptado. VI.1. Sobre la autonomía del Derecho.-VII. Criterios de tipificación e interpretación.-VIII. Conclusiones.-IX. Bibliografía. 


\section{LA SOCIEDAD ACTUAL BAJO EL PARADIGMA DE LA TECNOCIENCIA}

Apunta Beck que vivimos en la sociedad del riesgo ${ }^{1}$, una sociedad en continuo estado de alerta ante el peligro de inminentes catástrofes, pero el riesgo en sí no es nada, no es real sino que se convierte en real, en algo concreto, en el momento en que se anticipa. Como dice el teorema de Thomas, "si algunas situaciones son definidas como reales, ellas son reales en sus propias consecuencias». Si bien en todas las sociedades han existido riesgos, lo que caracteriza a la sociedad posmoderna es su incapacidad para gestionarlos; la propia sociedad genera riesgos que tienen un origen incierto y unas consecuencias indeterminadas ${ }^{2}$.

Así, en principio se podría pensar que objetivamente el nivel de seguridad de la sociedad actual es superior al de cualquier otra dado el conocimiento que se tiene sobre diversos fenómenos y el desarrollo de la ciencia y la tecnología. Los mecanismos de predicción y detección de catástrofes también han mejorado permitiendo ofrecer soluciones cada vez más adaptadas a las distintas circunstancias. El progreso de la tecnociencia, no obstante, tiene su lado amargo.

Por un lado, ese desarrollo de la ciencia y tecnología ha permitido importantes progresos en numerosas áreas, desde la medicina hasta la investigación química, nuclear o genética, reportando a su vez cuantiosos beneficios económicos a través de la mejora y abaratamiento de materiales, cambios en el sistema de producción o la deslocalización de procesos productivos, pero supone también considerar la posibilidad de fallos en el propio desarrollo de estos medios o en las consecuencias de su utilización. La propia sociedad se configura como "organización de riesgo» ${ }^{3}$ y su normal funcionamiento supone un aumento de situaciones de peligro.

${ }^{1}$ Beck, U. (2007), "Vivir en la sociedad del riesgo mundial. Living in the World Risk Society», Dinámicas interculturales, núm. 8, Barcelona.

2 Analizando estos conceptos más detenidamente, puede notarse que existe una clara diferencia entre riesgo y peligro, pese a que muchas veces se utilizan como sinónimos. La noción de riesgo remite a un ámbito más concreto que la de peligro. Como lo ejemplifica Serrano, "una inundación es un peligro, pero quien construye su casa en el cauce de un río se expone a un riesgo». En Serrano, J.L. (2007), "Capítulo 2. La diferencia riesgo/peligro», en Red Latinoamericana y Europea sobre Gobierno de los Riesgos, Derecho, sociedad y riesgos. La sociedad contemporánea vista a partir de la idea de riesgo, Brasilia, UniCEUB, UNITAR, pág. 65.

3 Castaldo, A. (1997), "La concreción del "riesgo jurídicamente relevante"», en Silva Sánchez, J.M. (ed.), Política criminal y nuevo Derecho penal. Libro homenaje a Claus Roxin, Barcelona, José María Bosch ed., págs. 233-242. 
En este marco surgirían los nuevos riesgos ${ }^{4}$, masivos y, lo que es más importante, incalculables tanto en su gravedad como en su extensión; catástrofes repentinas como un accidente nuclear o el hundimiento de un petrolero, o que se van produciendo paulatinamente como el calentamiento global y el deshielo ${ }^{5}$ habrían producido la pérdida de la fe en la ciencia que había caracterizado a la modernidad; su exactitud se ve ahora reemplazada por la indeterminación y la incertidumbre ${ }^{6}$.

Así, estos problemas intrínsecos al desarrollo de la tecnociencia se acrecientan exponencialmente por las características de las sociedades actuales.

En primer lugar, se ha de considerar el carácter expansivo de la actividad científica y tecnológica. Espacios que antes permanecían al margen de la intervención tecnocientífica, o bien esta estaba reducida a cotas muy bajas, se ven ahora colonizados al completo por la tecnociencia, quedando supeditados a las reglas que determinan su funcionamiento. No se habla tanto de grandes progresos genéticos o nucleares como de la incorporación de estos avances en el día a día.

En segundo lugar, los espacios ganados a la naturaleza ${ }^{7}$ suponen otra área de expansión que antes permanecía ajena al control, dominio o previsión por parte del ser humano. Se habla aquí del control y mejora del aprovechamiento de los recursos naturales, de la predicción de los fenómenos potencialmente catastróficos y de la ganancia literal de espacio al entorno, es decir, la utilización por parte del hombre de zonas antes dominadas por la naturaleza y obtenidas gracias al desplazamiento del curso de un río, al drenaje de un pantano, a la creación de islas artificiales, etc.

Como señala Mendoza, la principal diferencia de esta época con otras anteriores es el carácter manufacturado o artificial de los peligros surgidos. "Estos nuevos riesgos surgen como consecuencias secundarias ('Nebenfolgen') del progreso tecnológico, esto es, producidos por el impacto de la actividad humana para controlar u dominar múl-

${ }^{4}$ En profundidad, véase exposición de Beck de «los macropeligros: los escándalos ocultados» en su obra Politicas ecológicas en la Edad del Riesgo. Antídotos. La irresponsabilidad organizada, Barcelona, El Roure, págs. 144 y sig.

5 Mendoza Buergo, B. (2003), «Gestión del riesgo y política criminal de seguridad en la sociedad del riesgo", en Da Agra, C. et al., La seguridad en la sociedad del riesgo. Un debate abierto, Barcelona, Atelier, pág. 68.

${ }^{6}$ Campione, R. (2003), «El que algo quiere algo le cuesta: notas sobre la killateralschädengesellschaft», en Da Agra, C. et al., ob. cit., pág. 19.

7 Esteve Pardo, J. y Tejada Palacios, J. (2013), Ciencia y Derecho: la nueva división de poderes, Madrid, Fundación Coloquio jurídico europeo. 
tiples procesos; por tanto, se trata de efectos indeseado, a menudo no previstos y a veces imprevisibles de un actuar humano, inicialmente dirigido a fines positivamente valorados» ${ }^{8}$. La extensión del riesgo, cuantitativa y cualitativamente, es cada vez mayor porque la expansión de la tecnociencia también lo es.

Por otra parte, la tercera característica a destacar de las sociedades actuales es sin duda la creciente complejidad que van adquiriendo. Como señala Silva, se ha incrementado enormemente la interacción individual debido a la cooperación y división funcional de procesos $^{9}$, lo que aumenta a su vez las conexiones causales y la dificultad, cuando no imposibilidad, de establecerlas con claridad ${ }^{10}$. En este sentido, habla Beck de «irresponsabilidad organizada» ${ }^{11}$. La complejidad de las organizaciones hace que el rol del individuo, aisladamente considerado, resulte insignificante para la totalidad del daño, por lo que la percepción de su responsabilidad es escasa ${ }^{12}$.

Afirma Esteve que las sociedades actuales han superado en parte el peligro de hambre e inanición aceptando los riesgos generados por la industria alimentaria; de abastecimiento de energía, asumiendo los peligros de las nuevas fuentes de obtención; las enfermedades naturales a cambio de los riesgos derivados de la industria farmacéutica. Incluso se debe asumir los riesgos que la propia sociedad genera al tratar de eliminar otros riesgos. Así, "los riesgos creados por la sociedad industrial contaminando las aguas son ya en buena medida eliminados por la actuación técnica de saneamiento y

${ }^{8}$ Mendoza Buergo, B. (2003), cit., pág. 69.

9 Silva Sánchez, J.M. (1999), La expansión del Derecho penal. Aspectos de la política criminal en las sociedades postindustriales, Madrid, Civitas, pág. 23.

${ }_{10}$ Mendoza Buergo, B. (2003), cit., págs. 69-70.

11 Beck, U. (2002), La sociedad del riesgo global, Madrid, Siglo XXI de España editores.

12 En este sentido, señala Schünemann que «la peculiaridad de la sociedad industrial actual estriba únicamente en el extraordinario incremento de las interconexiones causales. Pues debido a la extremadamente densa red de industrialización existente, en muchos ámbitos resulta imposible explicar, por ejemplo, la producción de daños en la salud de los habitantes de una determinada zona a través de una sola relación de causalidad, con base en la cual pudiese identificarse, por ejemplo, la emisión de sustancias tóxicas por parte de una determinada fábrica como causa. Por el contrario, es característico de la sociedad industrial actual la existencia de relaciones causales múltiples cuyo esclarecimiento en detalle es de todo punto imposible con los métodos e instrumentos científico-naturales actuales a causa de su interrelación y de su compleja confluencia. El segundo elemento característico de la "sociedad de riesgo» es la sustitución de los contextos de acción individuales por contextos de acción colectivos, en los que el contacto interpersonal es reemplazado por una forma de comportamiento anonimizada y estandarizada», en (1996), "Consideraciones críticas sobre la situación espiritual de la ciencia jurídico-penal alemana», $A D P C P$, tomo XLIX, I, págs. 198-199.

(C) UNED. Revista de Derecho UNED, núm. 23, 2018 
depuración, pero esa actividad genera nuevos riesgos en forma de fangos o biosólidos frente a los que no se ha reaccionado debidamente por el momento ${ }^{13}$.

\section{COLISIÓN INTERCIENTÍFICA: CONSECUENCIAS DE LA DISPAR NATURALEZA DE LA ACTIVIDAD TECNOCIENTÍFICA Y LA JURÍDICA}

La actividad tecnocientífica es un área que opera tolerando grandes dosis de incertidumbre y que, en no pocas ocasiones, ha supuesto el peor de los resultados posibles. Baste recordar algunos de los principales accidentes científicos y/o tecnológicos de las últimas décadas:

- En 2001, la explosión de una plataforma petrolífera en el Golfo de México supuso la muerte de once trabajadores y un vertido estimado en 779.000 toneladas de crudo $^{14}$.

- En 2012, la firma Knight Capital pierde alrededor de 500 millones de dólares en una hora debido a un fallo informático que supuso que el software compraventa de acciones funcionara sin control humano ${ }^{15}$.

- El accidente nuclear de la central de Chernóbil en 1986 tuvo unas consecuencias devastadoras tanto en términos humanos como medioambientales. Transcurridos más de trienta años, aun se evalúan las consecuencias dado que la contaminación en la zona no ha cesado ${ }^{16}$.

- También en los años ochenta, los errores ocasionados por la máquina de radioterapia Therac- 20 supuso que en al menos seis ocasiones diversos pacientes sufrieran sobredosis de radiación ${ }^{17}$.

- A finales de 1984, fue detectado un escape de gas en fábrica de pesticidas en Bhopal. Según las cifras de Amnistía Internacional, entre 7.000 y 10.000 personas murieron en los tres días

13 Esteve Pardo, J. (1999), Técnica, riesgo y Derecho. Tratamiento del riesgo tecnológico en el Derecho ambiental, Barcelona, Ariel, pág. 30.

${ }^{14}$ Cfr. https://goo.gl/sBtp6g [fecha de consulta: 10/01/2018].

15 Cfr. https://goo.gl/hrzhsJ [fecha de consulta: 10/01/2018].

${ }^{16} \mathrm{Cfr}$. https://goo.gl/wLngHq Sobre los resultados, cfr. el informe de la OECD accesible en: http://www.oecd-nea.org/rp/chernobyl/c0e.html [fecha de consulta: 10/01/2018].

${ }^{17}$ Cfr. https://goo.gl/ChfZxy [fecha de consulta: 10/01/2018]. 
posteriores al accidente y cerca de 570.000 se vieron expuestas a niveles nocivos de toxicidad ${ }^{18}$.

- En 1995 se detecta la primera transmisión a humanos de la encefalopatía espongiforme bovina, comúnmente conocida como enfermedad de las vacas locas, causada por la alimentación suplementaria del ganado bovino con restos de otros animales portadores de la enfermedad pero no transmisible a humanos en su caso ${ }^{19}$.

— En 2014, The Home Depot, una tienda de bricolaje internacional, confirmaría la vulneración de sus sistemas de pago por el que fueron afectadas 56 millones de tarjetas ${ }^{20}$.

- A comienzos de 1986, el mundo entero contemplaba en directo la desintegración del trasbordador espacial Challenger a los pocos segundos de su despegue, con la consiguiente muerte de toda su tripulación ${ }^{21}$.

- Comercialización de la talidomida en la década de los sesenta supuso el nacimiento de miles de bebes con malformaciones ${ }^{22}$.

Las causas de los supuestos expuestos difieren en gran medida pero en todos los casos se trata de riesgos - materializados- inherentes a la actividad tecnocientífica.

Es sabido que la actividad científica avanza a base de ensayo y error. Su finalidad, su racionalidad, está encaminada a la búsqueda de la verdad por lo que no tiene inconvenientes en convivir con altas dosis de incerteza el tiempo que sea necesario en tanto pueda alcanzarla. Siempre será preferible el desconocimiento a dar por válida determinada hipótesis a sabiendas de su falsedad.

Distinto es, como ocurre con frecuencia, que con el tiempo las soluciones adoptadas devengan ineficaces. Es posible que desde el primer momento no fuesen aptas para resolver determinado problema o bien, siéndolo al principio, se volvieran insuficientes con el paso del tiempo. En estos casos, no se ha de esperar a tener una nueva solución sino que las erróneas pierden vigencia de modo inmediato, permaneciendo el problema irresuelto en tanto no surja la respuesta óptima.

${ }^{18} \mathrm{Cfr}$. https://goo.gl/YDG0N6 [fecha de consulta: 10/01/2018].

${ }^{19}$ Cfr. https://goo.gl/H16iu8 [fecha de consulta: 10/01/2018].

${ }^{20}$ Cfr. https://goo.gl/7Q84Jv [fecha de consulta: 10/01/2018].

${ }^{21}$ Cfr. https://goo.gl/NNPEHx [fecha de consulta: 10/01/2018].

${ }^{22}$ En profundidad, cfr. https://goo.gl/SbNLth [fecha de consulta: 10/01/2018]. 
En el Derecho esto resulta inimaginable. Su racionalidad no se desarrolla en pos de la verdad sino de la justicia. Su principal misión no es buscar verdades sino evitar el caos en la sociedad, lo cual sólo podrá lograr aportando seguridad jurídica. La aproximación a la verdad es deseable pero no prioritaria, siempre estará supeditada a su finalidad primera.

Lógicamente, al tener finalidades diferentes, operan con distintas racionalidades. A diferencia de las ciencias de la naturaleza, el Derecho no puede permanecer en la ignorancia, no puede guardar silencio hasta que la verdad sea hallada, puesto que la realidad sobre la que incide requiere respuestas inmediatas. Los conflictos sociales, la prevención de conductas dañinas, no pueden permanecer eternamente postergados, necesitan una decisión inmediata que sea lo más certera, veraz y justa posible.

Así, la racionalidad que debe entenderse asumida por el Derecho es una racionalidad acotada, limitada. El propio conocimiento de la realidad resulta materialmente inabarcable para el Derecho, aunque tampoco es prioritario alcanzarlo. Es decir, resultaría deseable un conocimiento exhaustivo de la realidad sobre la que se pretende incidir pero dado que esto es del todo imposible, debe suplir los vacíos de conocimiento con ficciones y presunciones. En el campo jurídico, no hay mayor inconveniente en crear aquella parte de la realidad que se desconoce siempre que los destinatarios de las normas conozcan de antemano su contenido. Sólo así podrán moverse con la seguridad que aporta el conocimiento de las reglas dominantes en la sociedad. Sólo así habrá seguridad jurídica.

El otro componente de esta racionalidad acotada son los filtros a través de los cuales el Derecho tamiza la realidad. Los principios y valores vienen a aportar un plus de seguridad a los ciudadanos toda vez que suponen un límite al ejercicio de la coacción estatal. La obtención de la verdad, nuevamente, se encuentra supeditada al respeto de determinadas garantías y reglas que deben regir en un estado de Derecho.

\section{PROBLEMAS ASOCIADOS A LA INTERVENCIÓN ESTATAL EN EL CONTROL DE RIESGOS}

Considérese el siguiente supuesto real descrito por Esteve: "unas emanaciones provenientes de unos laboratorios en las cercanías de una ciudad originaron una nube de gases que produjeron irritaciones e impidieron totalmente la visión a los vecinos de la zona. 
Se creó una situación de pánico, no se pudo abandonar la zona por falta absoluta de visibilidad y los vehículos que lo intentaron sufrieron aparatosas colisiones. Aunque no se produjeron víctimas, se tardó un buen tiempo en determinar si se trataba o no de gases tóxicos» ${ }^{23}$.

Se presentan aquí todos los elementos que se vienen describiendo como riesgos típicos de las sociedades actuales. Ante la alarma generada, como suele ser habitual, la empresa se apresuró en señalar un fallo humano como causante del accidente, lo que en cierta medida tranquiliza a la ciudadanía. Un fallo es siempre evitable. Como expone el autor, sería aterrador saber que, pese a haberse actuado con la máxima diligencia y siguiendo todos los protocolos establecidos, el accidente se produjo por causas científicamente desconocidas. "Nada tranquilizador resulta, incluso estremece, que ante un accidente, ante un incontrolado nivel de emisiones, no puedan establecerse con una mínima exactitud sus causas y reconocer en definitiva que científica o técnicamente se desconocen los procesos desencadenados en punto a sus orígenes o efectos ${ }^{24}$. Desconociendo las causas y consecuencias, no es posible investigar y desarrollar medios eficaces para evitar nuevos accidentes.

La sociedad, apunta Quintero Olivares, "ha creado el «estado de riesgo» como medio natural» ${ }^{25}$. En este contexto, se reclama una acción del Estado que venga a paliar el riesgo que el desarrollo de estas actividades conlleva. Sin renunciar al progreso, se pretende una legislación que venga a librar a la ciudadanía de las consecuencias negativas que el desarrollo tecnocientífico supone ${ }^{26}$.

Ante esta tesitura, los Estados debe decidir no sólo sobre la necesidad de intervención y regulación sino también sobre la contundencia de la misma. Básicamente, se debe responder a la siguiente pregunta: ¿cuánto riesgo estamos dispuestos a aceptar?

${ }^{23}$ Esteve Pardo, J. (1999), cit., pág. 34.

${ }^{24}$ Ibíd., pág. 35.

${ }^{25}$ Quintero Olivares, G. (2003), «Los delitos de riesgo en la política criminal de nuestro tiempo», en Arroyo Zapatero, L., Neumann, U. y Nieto Martín, A. (coords.), Crítica y justificación del Derecho penal en el cambio de siglo. El análisis crítico de la Escuela de Frankfurt, Cuenca, Universidad de Castilla-La Mancha, pág. 244.

${ }^{26}$ Como señala Campione, "el tránsito a la nueva configuración social conlleva una transformación fundamental en el sistema axiológico colectivo. Mientras las sociedades industriales reposaban en una dinámica valorativa dirigida a la búsqueda ideal de la igualdad, la sociedad del riesgo desarrolla, como tensión ideal normativa, la idea de seguridad». En Campione, R. (2003), cit. pág. 18. 
Entiende Herzog 27 , que estas situaciones enfrentan al legislador al trilema regulador: o bien existe una ignorancia mutua entre el Derecho y la sociedad; o bien hay una desintegración de lo social por el efecto colonizador de la intervención del Derecho ${ }^{28}$; o bien hay una desintegración del Derecho por las continuas demandas sociales de regulación atendidas por el legislador sin mayor reflexión en cuanto a su necesidad.

La situación más habitual suele ser la tercera. Con mayor o menor justificación, el Derecho trata de gestionar el riesgo limitando y encauzando las actividades científicas y tecnológicas potencialmente peligrosas.

Se produce entonces el choque que se viene anticipando. El Derecho debe decidir en situaciones de incertidumbre con el hándicap de que su decisión será determinante a la hora de prevenir posibles daños. Como señala Esteve, "este reto ineludible que al Derecho se le plantea no es otro que el de la decisión en situaciones de incerteza. Esa irrenunciable función decisoria es una de las grandezas del Derecho pero también una de sus servidumbres, que se hace gravosa y muy compleja cuando esa decisión debe adoptarse en entornos de incertidumbre... Las ciencias experimentales pueden detectar -y generarcada vez con más frecuencia, situaciones y entorno de incertidumbre que normalmente se expanden con los propios vanes de la ciencia que nos abre nuevas posibilidades y nos introduce en terrenos desconocidos; pueden perfectamente reconocerse incapaces de emitir un veredicto sobre muchas cuestiones que se les plantean por la precariedad de los conocimientos de que disponen y los márgenes de incertidumbre que se abren» ${ }^{29}$.

Al ser imposible para el Derecho el conocimiento de las actividades científicas con la profundidad que sería deseable para su regulación, no le queda más remedio que ir cediendo al campo científico parcelas de actuación, produciéndose en cierto sentido una dejación de sus funciones. La otra cara de la desintegración del Derecho de la que se hablaba anteriormente no está en manos de los grupos sociales demandantes de seguridad sino de la tecnociencia - y cuantos

${ }^{27}$ Herzog, F. (1993), «Límites al control general de los riesgos sociales:(una perspectiva crítica ante el Derecho Penal en peligro)», $A D P C P$, tomo XLVI, I, págs. 319-320.

${ }^{28}$ En profundidad, Habermas, J. (1992), Teoría de la acción comunicativa II. Crítica de la razón funcionalista, Madrid, Taurus, págs. 514 y sig.

${ }^{29}$ Esteve Pardo, J. y Tejada Palacios, J. (2013), cit., págs. 11-12. En idéntico sentido, Esteve Pardo, J. (1999), cit. y, del mismo autor, (2009), El desconcierto del Leviatán..., cit. 
grupos de interés giran en torno a ella- al ser la determinante de los niveles de riesgo inherentes a su propia actividad y que serán la base para la posterior decisión legislativa.

Esta situación puede verse reflejada en los numerosos casos en los que la legislación remite al «estado de la técnica», a la «mejor tecnología disponible» o similares ${ }^{30}$. Se trata de la asunción por parte del Estado de su incapacidad para seguir la complejidad y rapidez de la evolución tecnocientífica.

Del mismo modo, el Derecho también cede espacios de actuación cuando deja en manos de grupos de expertos la regulación de la propia actividad y la evaluación del peligro que esta conlleva. La Administración suele delegar en particulares la evaluación de los riesgos a través de la creación de agencias, entidades y organizaciones ${ }^{31}$ encargadas de diversas funciones entre las que destacan la elaboración de protocolos de actuación y la determinación, como se ha dicho, del peligro inherente a la actividad, tanto de un modo individual mediante la emisión de certificados, como a nivel general, sobre la peligrosidad de un sector determinado.

Dejando de lado los problemas suscitados en torno a la atribución de responsabilidades por el ejercicio de su actividad, se entiende que su institución constituye un modo de objetivizar la evaluación del riesgo y, por ende, la necesidad de intervención estatal.

Así, la evaluación de la peligrosidad permanece en manos de quienes mejor comprenden su funcionamiento y potencialidades lesivas, aunque con las limitaciones que se han expuesto. La última decisión sobre la acción a emprender, en cambio, queda reservada a la Administración, que será la responsable de determinar el nivel de riesgo que está dispuesta a asumir. Es decir, cuanto más temerosa o prudente sea la Administración, más anticipará la intervención y mayor será el control que ejerza sobre dichas actividades, llegando en los casos extremos a la prohibición de determinadas conductas.

30 Esteve Pardo, J. (1999), cit., pág. 20.

31 En profundidad, Hermitee, M.A. (2007), «Capítulo I. La fundación jurídica de una sociedad de las ciencias y la técnica a través de las crisis y de los riesgos», en Red Latinoamericana y Europea sobre Gobierno de los Riesgos, cit., págs. 13-63; y Esteve Pardo, J. y Tejada Palacios, J. (2013), cit., págs. 94 y sig. y Esteve Pardo, J. (2002), Autorregulación. Génesis y efectos, Cizur Menor, Aranzadi. 


\section{FUNDAMENTOS DEL CONTROL PENAL DEL RIESGO}

Las situaciones potencialmente riesgosas, el legislador deberán ser controladas por el legislador del modo menos lesivo. Procurando el mal menor, se tendrá que optar por aquella regulación que resulte menos invasiva para la vida de las personas, ya que no se trata de proteger bienes jurídicos sacrificando injustificadamente otros.

Claro que en este punto será determinante la función que se le otorgue al Derecho penal y, en última instancia, al Derecho que, conviene recordar, no es un elemento neutral. Si el Derecho pretende garantizar la pacífica convivencia en sociedad deberá reducir sus intervenciones al mínimo a efectos de evitar limitaciones innecesarias de la libertad de las personas. Con mayor razón, el Derecho penal deberá reducirse aún más ya que su intervención supone un ataque directo contra diversas manifestaciones de esa libertad. Su necesidad, no obstante, se fundamenta en su utilidad a la hora de garantizar dicha convivencia, lo que sólo podrá alcanzarse mediante la protección de las partes más débiles de la sociedad, esto es, únicamente ofreciendo a todos las mismas posibilidades de desarrollo de la personalidad y paliando las situaciones de injusticia que se originan en torno a la ostentación de poder.

La protección de esos mínimos de convivencia es la protección de bienes jurídicos penales ${ }^{32}$ que no sólo servirá de límite a cada intervención legislativa sino que constituye su único fundamento. En ningún caso deberá suponer un obstáculo y mucho menos un pretexto para la prohibición, por lo que su actualización ha de ser constante. La tutela de bienes jurídicos que no son realmente valorados por la sociedad carece de legitimación y su imposición no es más que un mero ejercicio de poder.

En este sentido, los bienes jurídicos han evolucionado a lo largo del tiempo, dejando atrás concepciones morales y autoritarias para centrarse cada vez más en la protección de la persona y las condiciones esenciales para su convivencia en sociedad. Así, el reconocimiento de bienes jurídicos colectivos ${ }^{33}$ viene a complementar la tu-

32 Sobre la distinción entre «bien jurídico» y «bien jurídico penal», cfr. Mir Puig, S. (1989), «Bien jurídico y bien jurídico-penal como límite del ius puniendi», Estudios penales y criminológicos, núm. 14, 1989-1990, págs. 203-216. Sobre la evolución del concepto de bien jurídico, Hormazábal Malarée, H. (1992), Bien jurídico y Estado social y democrático de Derecho. El objeto protegido por la norma penal, 2. ${ }^{\text {a }}$ ed., Santiago de Chile, Editorial Jurídica ConoSur; y Mir Puig, S. (2003), cit., págs. 112 y sig.

${ }^{33}$ No es pacífico definir los bienes jurídicos colectivos. Siguiendo a Hefendehl, se destacan los conceptos de "no exclusión en el uso», "no rivalidad en el consumo» 
tela de la esfera individual contemplada hasta entonces, añadiendo intereses que, si bien se alejan de ser pacíficamente aceptados, pueden entenderse de gran relevancia en el modelo social actual. En cualquier caso, como señala Mir, debe quedar claro que al Estado social y democrático "le importan los intereses colectivos en la medida en que condicionan la vida de los individuos" ya que "se trata de que el sistema social se ponga al servicio del individuo, no de que el individuo esté al servicio del sistema» ${ }^{34}$.

Es en este marco donde se introduce o refuerza la protección penal de determinados bienes jurídicos considerados en peligro por el normal funcionamiento de la actividad tecnocientífica propia de las sociedades modernas ${ }^{35}$. Se trata de bienes cuya dañosidad, se entiende, va más allá del posible perjuicio para la vida, la integridad física o los bienes de las personas. Están en riesgo intereses que afectan a toda la comunidad e incluso a los de generaciones futuras. Es en este sentido en el que se encamina la protección del medio ambiente, la salud pública, la identidad genética y la seguridad nuclear, entre otros.

Como se ha comentado anteriormente, el propio discurrir de la sociedad actual supone un peligro constante, con un potencial lesivo superior al de sociedades pretéritas ${ }^{36}$. Esta potencialidad, no obs-

y «no distribuibilidad». En Hefendehl, R. (2002), «¿Debe ocuparse el derecho penal de riesgos futuros? Bienes jurídicos colectivos y delitos de peligro abstracto», RECPC, 04-14, pág. 4.

${ }_{34}$ Mir Puig, S. (1989), cit., pág. 212. No obstante, guarda razón Moccia al señalar las dificultades que surgen al tratar de dotar de contenido el concepto de bien jurídico, ya que "no se halla en condiciones de ofrecer una fórmula con la cual, mediante operaciones de subsunción y deducción, se pueda delimitar fácilmente la conducta punible de la que no lo es», en Moccia, S. (1997), "De la tutela de bienes a la tutela de funciones: entre ilusiones postmodernas y reflujos liberales», en Silva Sánchez, J.M. (ed.), Política criminal..., cit., pág. 114. Pese a los diversos intentos de concretarlo y objetivizarlo, su materialización siempre será fruto de una decisión legislativa surgida de una previa valoración dentro, eso sí, del mayor consenso posible.

${ }^{35}$ Como señala Ruiz Rodríguez, algunos casos de enorme relevancia "han obligado a los responsables públicos, aún es pronto para afirmar que con éxito, a adoptar politicas de protección de la salud de las personas que reconozcan aquellos avances científicos como una necesidad y, a su vez, como un potencial riesgo para esa salud elevada a interés básico de convivencia y merecedora de la máxima protección», en Ruiz Rodríguez, L.R. (2016), "La reforma penal de los delitos contra la salud pública como respuesta a las innovaciones científicas y tecnológicas», $R E C P C, 18-19$, pág. 2.

${ }^{36}$ En este sentido, Fierro, G.J. (2002), Causalidad e imputación, Buenos Aires, Astrea, págs. 379 y sig.; y Diez Ripollés, J.L. (2006), «De la sociedad del riesgo a la seguridad ciudadana un debate desenfocado», en Cancio Meliá, M. y Gómez-Jara Díez, C., Derecho penal del enemigo: el discurso penal de la exclusión, vol. 1, Madrid, Edisofer págs. 553-602. 
tante, deberá ser concretada a efectos de determinar si tiene la suficiente entidad como para acudir a la protección penal ${ }^{37}$. De este modo, el legislador se enfrenta a la difícil tarea de evaluar los riesgos del modo más objetivo posible, procurando alejarse de las subjetividades, el temor y las presiones que dichas conductas generan ${ }^{38}$.

Conviene recordar que cualquier limitación en materia tecnocientífica supone un obstáculo al propio progreso estatal, no sólo en cuanto al avance del conocimiento se refiere, sino también en torno a la actividad económica que lo rodea. La inversión en investigación debiera ser un interés de primer orden para el Estado, como demuestra el hecho de ser un valor constitucionalmente protegido ${ }^{39}$, por lo que toda limitación que este realice supone una rémora contra sus propios intereses ${ }^{40}$, excepto que se realice en pos de un valor superior.

El riesgo jurídicamente relevante comienza allí donde termina el riesgo permitido ${ }^{41}$. Siguiendo los criterios apuntados por Castaldo ${ }^{42}$, su determinación estará conformada por elementos subjetivos y objetivos. Entre estos últimos, los datos empíricos relativos a la can-

37 Sobre el papel de los comités científicos en la determinación del riesgo, véase supra y, en profundidad, Cierco Seira, C. (2004), «El principio de precaución: reflexiones sobre su contenido y alcance en los derechos comunitario Y español», Revista de Administración Pública, núm. 163, págs. 73-125; y Montoro Chiner, M.J. (2005), «Perspectivas de contraste ante el riesgo ecológico. Agentes que intervienen en la evaluación del riesgo. En especial, los comités científicos», en Buxó, M.J. y Casado, M. (coords.), Riesgo y precaución. Pasos hacia una bioética ambiental, Barcelona, Residènca d'Investigadors CSIC-Generalitat de Catalunya, págs. 125-136, que destaca la reducción de la conflictividad que supone la cesión de las decisiones a un grupo de expertos debido, a su entender, de una doble causa: "el celo y la diligencia con que los expertos, componiendo por lo general un grupo interdisciplinar, se comportan, o la convicción de los particulares de que la simbiosis órganos administrativos-comités de expertos aglutina un nivel de experiencia y de legitimación política difícil de superar», pág. 130.

${ }^{38}$ En el ámbito administrativo, cfr. Terradillos Basoco, J.M. (1992), cit., pág. 79. Aunque, como señala Quintero Olivares, el Derecho penal no es el instrumento adecuado para ofrecer seguridad a la ciudadanía. Quintero Olivares, G. (2013), Derecho penal ambiental, Valencia, Tirant lo Blanch, pág. 70 .

${ }^{39}$ Gracia Martin, L. y Escuchuri Asia, E. (2005), cit.

40 Beltrán García-Echániz, A. (2010), «El desarrollo de la política científica y tecnológica en España», en Romeo Casabona, C.M. y Sánchez Lázaro, F.G. (eds.), La adaptación del Derecho penal al desarrollo social y tecnológico, Granada, Comares, págs. 3-23. Sobre el problema de los falsos positivos, cfr. Prieto Molinero, R.J. (2005), El riesgo de desarrollo: un supuesto paradójico de la responsabilidad por el producto, Madrid, Dykinson, págs. 444 y sig.

${ }^{41}$ Quintero Olivares, G. (2013), cit. En profundidad, Paredes Castañón, J.M. (1995) El riesgo permitido en Derecho Penal (régimen jurídico-penal de las actividades peligrosas), Madrid, Ministerio de Justicia e interior.

42 Castaldo, A. (1997), cit., págs. 233-242. 
tidad y cualidad de los fenómenos guardarán relación con la frecuencia con la que el suceso se produce y la peligrosidad del mismo, respectivamente. Así, por ejemplo, los accidentes nucleares son poco frecuentes pero su dañosidad podría alcanzar cotas elevadísimas para la sociedad en su conjunto. La contaminación acústica, en cambio, tiene una frecuencia mayor aunque su lesividad es mucho más reducida.

El factor valorativo apuntado por Castaldo es el relativo a la utilidad social de la conducta, que será determinante para el legislador a la hora de evaluar la tolerancia con el peligro.

A las dificultades que presenta la evaluación de riesgos ha de añadirse la dosis de incertidumbre que, con mayor o menor énfasis, está presente en toda actividad científica. En este sentido, desde la década de los sesenta del pasado siglo se viene hablando de la incorporación del principio de precaución al Derecho penal.

Los orígenes de este principio suelen situarse en Alemania, en relación al control de riesgos potencialmente lesivos en materia de Derecho administrativo medioambiental ${ }^{43}$. Desde entonces, se ha ido citando en diversos documentos internacionales hasta que alcanzara su mayor relevancia con su incorporación en la Declaración de Río sobre medioambiente y desarrollo, adoptada con ocasión de la Conferencia sobre la materia celebrada en 1992. El principio 15 establece que «con el fin de proteger el medio ambiente, los Estados deberán aplicar ampliamente el criterio de precaución conforme a sus capacidades. Cuando haya peligro de daño grave o irreversible, la falta de certeza científica absoluta no deberá utilizarse como razón para postergar la adopción de medidas eficaces en función de los costos para impedir la degradación del medio ambiente». Es decir, se incita a los gobiernos a legislar preventivamente cuando se den dos elementos: incertidumbre sobre el potencial lesivo de una actividad determinada y sospechas de que puede generar daños graves e irreversibles ${ }^{44}$.

${ }^{43}$ En profundidad, Gómez Tomillo, M. (2014), Principio de precaución y derecho punitivo del Estado, Tirant lo Blanch, edición electrónica sin paginar; Aguilar, S. y Jordan, A.J. (2003), "Principio de precaución, políticas públicas y riesgo», Política y Sociedad, vol. 40, núm. 3, págs. 61-79; Cruz Bottini, P. (2007), "Principio de precaución, Derecho penal y sociedad de riesgos", Revista General de Derecho penal, núm. 7; y Bonamigo, E.L. (2010), El principio de precaución: un nuevo principio bioético y biojurídico, Tesis doctoral, Universidad Rey Juan Carlos.

${ }^{44}$ Como señala Cierco, «la gestación de estos documentos se produce, como se sabe, en un contexto de creciente sensibilidad ante problemas tan graves como el calentamiento global del planeta y el correlativo cambio climático, el deterioro de la capa de ozono, la lluvia acida, el avance de la desertización o la gestión de los residuos radioactivos, por citar ejemplos bien conocidos. La lucha contra estos riesgos ambienta-

(C) UNED. Revista de Derecho UNED, núm. 23, 2018 
En el mismo año de 1992, el Tratado de Maastricht lo incorporaría al derecho comunitario señalando que la política medioambiental de la Comunidad estaría basada en los principios de cautela y acción preventiva ${ }^{45}$. A partir de entonces, el principio va a quedar definitivamente asentado en el plano normativo y jurisprudencial $^{46}$.

La extensión del principio de precaución no sólo se ciñe al Derecho medioambiental sino que paulatinamente se ha ido extendiendo por diferentes áreas ${ }^{47}$ tales como alimentación, salud, organismos genéticamente modificados, etc. ${ }^{48}$. Lógicamente, la jurisprudencia europea se ha hecho eco de idéntica ampliación invocándolo de un modo directo en casos de lo más diversos ${ }^{49}$, y llegando incluso a de-

les exigía -y exige, claro es - el compromiso decidido de la entera comunidad internacional, de suerte tal que los Estados debian promover un cambio de actitud en sus respectivas políticas», en Cierco Seira, C. (2004), cit., págs. 82-83. En el mismo sentido, destaca las dificultades de hacer frente a la criminalidad ecológica sin un enfoque coordinado, superador de las fronteras nacionales, Ruiz Rodríguez, L.R. (2009), «Limitaciones técnicas, jurídicas e ideológicas para el conocimiento y sanción de la criminalidad económica», Revista de Derecho penal y Criminología de la UNED, $3 .^{\text {a }}$ época, enero, págs. 347-394; y, del mismo autor, «Las catástrofes medioambientales y la aplicación de la Ley Penal en el espacio», Revista Eguzkiloren, 2003, núm. 17, págs. 47-56.

45 Concretamente, el art. 174 del citado Tratado establecía que « la política de la Comunidad en el ámbito del medio ambiente tendrá como objetivo alcanzar un nivel de protección elevado, teniendo presente la diversidad de situaciones existentes en las distintas regiones de la Comunidad. Se basará en los principios de cautela y de acción preventiva, en el principio de corrección de los atentados al medio ambiente, preferentemente en la fuente misma, y en el principio de quien contamina paga».

46 Es de destacar también la Comunicación de la Comisión Europea 2.2.2000 $\operatorname{COM}(2000)$ sobre el recurso al principio de precaución que viene a establecer las pautas que han de seguir los responsables políticos que se enfrente a la toma de decisiones a la hora de evaluar, valorar, gestionar y comunicar el riesgo. Así, las medidas a adoptar en caso de necesidad deberán ser proporcionadas según el interés protegido, no discriminatorias en su aplicación, coherentes con otras medidas similares adoptadas, basadas en el examen de costes y beneficios de la acción - y de la no acción-, sujetas a revisión según progrese el conocimiento científico y capaces de designar a quién incumbe aportar las pruebas científicas necesarias. Accesible en: https://goo.gl/zTIBAB [Fecha de consulta: 10/01/2018]

47 Sobre el procedimiento de evaluación y gestión de riesgos en la Unión Europea, cfr. Martínez Pérez, E. (2014), «El principio de cautela en la práctica internacional y europea: concepto, naturaleza jurídica y contenido», en Gómez Tomillo, M., cit., edición electrónica sin paginar.

${ }^{48}$ En profundidad, Bonamigo, E.L. (2010), cit.

${ }^{49}$ Ibíd., donde se cita jurisprudencia relativa a la alimentación humana, aves silvestres, contaminantes químicos y orgánicos, ensayos con animales, organismos genéticamente modificados, medicamentos, pesca, políticas medioambientales, productos defectuosos y productos fitosanitarios, entre otros. 
clararlo un principio general de Derecho comunitario en el asunto Artegodan en $2002^{50}$.

De este modo, el legislador nacional ha integrado el principio de precaución en la regulación civil y administrativa de diversas materias de las que pueda predicarse que existe una situación de incertidumbre y la eventualidad de producirse daños graves e irreversibles $^{51}$, lo que hace plantearse los posibles problemas que supondría su llegada, directa o indirecta, al Derecho penal ${ }^{52}$.

La problemática aludida resulta evidente toda vez que el principio supone un adelantamiento de la intervención estatal para regular - prohibir, en el caso penal- actividades donde lo que existen son meras sospechas de su potencial lesivo ${ }^{53}$. En Derecho penal,

50 Señalaba entonces el Tribunal: «Así pues, aunque únicamente se mencione en el Tratado en relación con la política de medio ambiente, el principio de cautela tiene un ámbito de aplicación más vasto. En aras de garantizar un alto nivel de protección de la salud, de la seguridad de los consumidores y del medio ambiente, dicho principio está destinado a aplicarse en todos los ámbitos de acción de la Comunidad... De lo anterior resulta que cabe definir el principio de cautela como un principio general del Derecho comunitario que impone a las autoridades competentes la obligación de adoptar las medidas apropiadas con vistas a prevenir ciertos riesgos potenciales para la salud pública, la seguridad y el medio ambiente, otorgando a las exigencias ligadas a la protección de estos intereses primacía sobre los intereses económicos». Sentencia del Tribunal de Primera Instancia de 26 de noviembre de 2002, Artegodan y otros/Comisión, asuntos acumulados T-74/00, T-76/00, T-83/00 a T-85/00, T-132/00, T-137/00 y T-141/00, núm. 183-184. Accesible en: https://goo.gl/iolz39 [fecha de consulta: $10 / 01 / 2018]$.

51 En profundidad, Romeo Casabona, C.M. (2004), "Aportaciones del principio de precaución al Derecho penal», en Romeo Casabona, C.M. (ed.), Principio de precaución, biotecnología y Derecho, Cátedra interuniversitaria Fundación BBVA-Diputación Foral de Bizkaia de Derecho y Genoma Humano-Bilbao-Granada, Comares, págs. 385 y sig. y Mendoza Buergo, B. (2004), «Principio de precaución, Derecho penal del riesgo y delitos de peligro», en Romeo Casabona, C.M. (ed.), Principio de precaución, cit., págs. 436-442.

${ }_{52} \mathrm{Cfr}$. el análisis jurisprudencial que al respecto realiza Sánchez Lázaro, F.G. (2010), «Deconstruyendo el riesgo permitido. Delitos contra la salud pública, principio de precaución, delitos contra la seguridad vial», Revista penal, núm. 25, págs. 136-150. Asimismo, Escobar Vélez, S. (2010), «El traslado del principio de precaución al Derecho penal en España», Revista Nuevo Foro Penal, vol. 6, núm. 75, julio-diciembre, págs. 15-40; Galán Muñoz, A. (2015), «La problemática utilización del principio de precaución como referente de la política criminal del moderno derecho penal. ¿Hacia un derecho penal del miedo a lo desconocido o hacia uno realmente preventivo? The use of the precautionary principle as a benchmark of the modern criminal policy in criminal law. Towards a criminal law of fear to unknown or to one really preventive?», REJ-Revista de Estudios de la Justicia, núm. 22, págs. 69-117; y Alonso Álamo, M. (2014), “¿Riesgos no permitidos? Observaciones sobre la incidencia del principio de precaución en el Derecho penal», en Gómez Tomillo, M., cit., edición electrónica sin paginar.

${ }_{53}$ Siendo, por lo demás, imposible demostrar la inexistencia de riesgos totales presentes y futuros. Como señalara el Abogado General J. Mischo en el asunto 
como es sabido, esto se traduce en la proliferación de delitos de peligro, conductas imprudentes y un dudoso acatamiento de los principios de lesividad y culpabilidad.

\section{EL MODELO DE TIPIFICACIÓN PENAL DE LA ACTIVIDAD CIENTÍFICA: EL TRINOMIO DE LA LEY PENAL EN BLANCO, LOS DELITOS DE PELIGRO Y EL CASTIGO DE LA IMPRUDENCIA}

La recepción del principio de precaución en el ámbito penal puede constatarse tanto de un modo directo como indirecto. En el primer caso, basta observar la proliferación de modalidades peligrosas e imprudentes de los tipos delictivos relacionados con la actividad científica, y el adelantamiento de las barreras punitivas que su introducción supone. Indirectamente, porque estos delitos están caracterizados por un tercer elemento que es el de las constantes remisiones a normativa sectorial extrapenal que, como se ha expuesto anteriormente, está directamente inspirada en el principio de precaución y así lo refleja en su regulación.

Así, si se tienen en cuenta las conductas relacionadas con la tecnología nuclear y con la biotecnología, tanto en materia de genética como de sustancias, se conforma un grupo de delitos que son los relativos a la energía nuclear, manipulación genética, contra los recursos naturales, contra la salud pública y de manipulación de organismos.

Se trata de un grupo de delitos que pudiera parecer heterogéneo si se atiende a su interés tutelado, pero que cobra sentido al analizarlo desde el ámbito científico. Y desde dicho punto de vista, el legislador ha acudido a la única fórmula que parece ofrecerle cierta seguridad en el control de daños: el trinomio compuesto por las leyes penales en blanco, los delitos de peligro y el castigo de la imprudencia.

Greenpeace, asunto C-6/99, de 25 de noviembre de 1999, párr. 72, el principio de precaución no exige "que una actividad deba quedar prohibida o sometida a restricciones draconianas, cuando no pueda demostrarse científicamente la inexistencia absoluta del más mínimo riesgo, pues todo el mundo sabe que la prueba negativa no en vano ha sido calificada por los juristas de todos los tiempos de probatio diabólica». 


\section{V.1. Ciencia y remisiones legislativas}

Como se ha comentado, en esta materia son numerosas las remisiones normativas a la regulación extrapenal. Ya sea que se introduzcan expresamente ${ }^{54}$ o se desprenda de la redacción del tipo ${ }^{55}$, la especificidad de la materia requiere, por un lado, una regulación precisa y técnica de los pormenores de la actividad y, por otro, una continua evolución acorde con el progreso científico. Sólo mediante la introducción de leyes penales en blanco es posible la tutela eficaz de los distintos bienes jurídicos.

Huerta Tocildo ${ }^{56}$ plantea tres problemas que surgen en torno al empleo de esta técnica. En primer lugar, la remisión a normas con rango inferior al de ley, conculcando el principio de división de poderes y la reserva absoluta de ley formal propia del Derecho penal. En segundo lugar, la posibilidad en materia medioambiental de que una misma conducta se convierta en delictiva o no según el lugar de comisión, dado que la normativa variará conforme nos desplacemos por el territorio. Finalmente, la posibilidad de que la remisión sea de tal envergadura que imposibilite al ciudadano conocer con certeza las conductas prohibidas.

En relación al primer asunto, como se ha comentado, se entiende que la especificidad de las materias que ahora se tratan exige una actualización permanente dado que las concretas formas en que los distintos bienes jurídicos pueden verse vulnerados cambiarán conforme lo hagan las técnicas, métodos y el conocimiento científico, en general ${ }^{57}$.

Tampoco existe una vulneración del principio de legalidad desde el punto de vista formal. Como señala el Tribunal Supremo en la sentencia núm. 24/2004, de 24 de febrero, el hecho de que exista una

${ }^{54}$ Como en el caso de los arts. 325, 326, 326bis, 327, 345, 349, 359 a 361, 362 quinquies y 363.

${ }_{55}$ Así, arts. 159 a 161, 362, 341 a 343 y 364.

56 Huerta Tocildo, S. (2001), «Principios básicos del Derecho penal y el art. 325 del Código penal», Revista Penal, núm. 8, págs. 39-52.

${ }^{57}$ Cfr. por ejemplo, la STC núm. 101/2012, de 8 de mayo, relativa al delito de caza y pesca no autorizadas donde se afirma que «la remisión a las citadas normas extrapenales específicas es expresa y está además justificada en atención al bien jurídico protegido por la norma penal (la biodiversidad, los recursos naturales y el medio ambiente $y$, de modo particular, la fauna silvestre), habida cuenta de la complejidad técnica de la materia y el carácter variable del grado de protección de las especies cinegéticas, lo que hace imprescindible la acomodación de la normativa a esa evolución y justifica la remisión a la legislación administrativa para determinar las especies de caza autorizadas, sin necesidad de acudir a la constante actualización de la norma penal, que tiene... "una pretensión de relativa permanencia en el tiempo»». Del mismo modo, SSTC núm. 120/1998, de 15 de junio y 34/2005, de 17 de febrero.

(C) UNED. Revista de Derecho UNED, núm. 23, 2018 
ley que habilite la regulación estatal de la materia salva la normal penal de su posible inconstitucionalidad. No son legítimas, no obstante, las ulteriores remisiones.

La segunda cuestión planteada por Huerta tampoco se entiende que deba ser considerada un problema. Son precisamente las peculiaridades de ciertos bienes jurídicos, como el medio ambiente, las que exigen que se atiendan a las distintas características que presenta a lo largo de todo el territorio, por lo que los límites tolerados en un sitio necesariamente han de diferir de los permitidos en otro.

El tercer problema apuntado, no obstante, es el que se origina en torno a determinadas normas penales en blanco en relación a las remisiones in totum. Como se ha mencionado, el aspecto formal del principio de legalidad y la taxatividad que se deriva del mismo exige certeza y precisión en la redacción de conductas y penas a efectos de no vulnerar la seguridad jurídica requerida. Esto es, en definitiva, una exigencia de que el grado de determinación de la conducta típica sea tal que pueda ser conocido por el ciudadano medio lo que es objeto de prohibición ${ }^{58}$.

Las remisiones a la normativa extrapenal no pueden contener la totalidad de la conducta. Como señala Terradillos Basoco, lo fundamental será que la ley «mantenga el monopolio sobre los elementos esenciales de la materia de prohibición ${ }^{59}$. En este sentido, es consolidada la jurisprudencia al respecto desde que la STC núm. 127/1990, de 5 de julio, asentara los requisitos que deben contener las normas penales en blanco para que su constitucionalidad no sea cuestionada ${ }^{60}$.

Entre las constantes remisiones contempladas en esta materia, no parece ajustarse a los requisitos apuntados la contemplada en

58 de Vicente Martínez, R. (2004), El principio de legalidad penal, Valencia, Tirant lo Blanch, edición electrónica sin paginar. En profundidad, Bacigalupo Zapater, E. (1999), Principios constitucionales de derecho penal, Buenos Aires, Hammurabi, págs. $45 \mathrm{y}$ sig.

59 Terradillos Basoco, J.M. (1996), «Protección penal del medioambiente en el nuevo Código penal español. Luces y sombras», Estudios penales y criminológicos, núm. 19, pág. 309. Sobre las remisiones en material de Derecho penal económico, del mismo autor (1995), Derecho penal de la empresa, Madrid, Trotta, págs. 204-205.

60 "[a] que el reenvío normativo sea expreso y esté justificado en razón del bien jurídico protegido por la norma penal; [b] que la ley, además de señalar la pena, contenga el núcleo esencial de la prohibición y [c] sea satisfecha la exigencia de certeza o, como señala la citada Sentencia 122/1987, se dé la suficiente concreción, para que la conducta calificada de delictiva quede suficientemente precisada con el complemento indispensable de la forma a la que la ley penal se remite, y resulte de esta forma salvaguardada la función de garantía de tipo con la posibilidad de conocimiento de la actuación penalmente conminada». 
el art. 326.2 CP tras la reforma operada por la LO 1/2015, de 30 de marzo ya que se castiga a "quien, fuera del supuesto a que se refiere el apartado anterior, traslade una cantidad no desdeñable de residuos, tanto en el caso de uno como en el de varios traslados que aparezcan vinculados, en alguno de los supuestos a que se refiere el Derecho de la Unión Europea relativo a los traslados de residuos».

La «cantidad no desdeñable» de residuos constituye un concepto que habrá de ser dotado de contenido mediante la praxis judicial pues es imposible saber a priori de qué volumen o tipo de residuos se está hablando. El problema se agrava si se contempla la restante redacción del precepto puesto que, en lugar de contener las distintas modalidades de realización de la conducta prohibidas, introduce expresamente una remisión al completo a la normativa de la Unión Europea.

Si a esto se añade el hecho de que el precepto constituye un cajón de sastre que recoge los supuestos no contemplados en el apartado anterior, cuya concreción también requiere acudir a la normativa extrapenal, nos encontramos con que el art. $326.2 \mathrm{CP}$ castiga a quienes "fuera de algunos supuestos a concretar, traslade una cantidad a determinar de residuos... en algunos de los supuestos a los que se refieren otras normas», lo que constituye, sin duda, el paradigma de la indeterminación y, por ende, de la inconstitucionalidad.

\section{V.2. Ciencia como sinónimo de peligro}

Entre las numerosas conductas contempladas, la gran mayoría se han configurado como delitos de peligro ${ }^{61}$, en su modalidad $a b s$ tracta en algunos $\operatorname{casos}^{62}$.

El recurso a los delitos de peligro suele ir asociado a la protección de bienes jurídicos colectivos ${ }^{63}$, donde la concreción del momento exacto de lesión resulta más difícil que en los delitos con bienes jurídicos individuales. La identidad genética, el medioambiente, la seguridad colectiva y la salud pública, pese a los cuestionamientos que en cuanto a su excesiva amplitud y dificultades de concreción

${ }^{61}$ Aunque no hay unanimidad en la doctrina, se entiende que constituyen delitos de peligro los recogidos en los arts. 160, 325 a 326bis, 342 a 345, 349, 359 a 362bis, 362quinquies y 363 a 365.

62 Tampoco existe acuerdo al respecto, pero pueden entenderse como delitos de peligro abstracto los contenidos en los arts. 160.2, 326.2, 360, 345.2, 363.5, 364.1, 364.2 y 365

63 Sobre el recurso a los delitos de peligro en este tipo de conductas, cfr. Hirsch, H.J. (2010), "Delitos de peligro y Derecho penal moderno», en Romeo Casabona, C.M. y Sánchez Lázaro, F.G. (eds.), cit., págs. 97-116. 
puedan surgir, podría afirmarse que constituyen bienes jurídicos de carácter colectivo.

Ahora bien, si se siguen los criterios anteriormente apuntados por Hefendehl para categorizar los bienes jurídicos como colectivos $^{64}$, esto es, su carácter de "no exclusión de uso» y «no distribuibilidad», debe llegarse a la conclusión que la «salud pública» ha de quedar fuera de este concepto por no ser más que la suma de bienes jurídicos individuales. Dado que siempre es posible su remisión a un sujeto concreto, el legislador debe tratar de acercar el castigo al momento de lesión introduciendo alguna referencia a esa individualidad. Es decir, alejarse del empleo de delitos de peligro abstracto y castigar, en su caso, la lesión o concreta puesta en peligro del bien jurídico, tal y como se desprende del principio de ofensividad. Como señala Feijoo Sánchez, «la sanción de una conducta por realizar algo que, simplemente, es estadísticamente peligroso, pero que en el caso concreto no supone una organización defectuosa para otro ámbito de organización sólo se puede canalizar a través del derecho administrativo» ${ }^{65}$.

Una modalidad específica que surge en torno a las modalidades de peligro es la paulatina introducción de los delitos de acumulación ${ }^{66}$, ya sea que se contemplen expresamente como en el caso de los delitos medioambientales ${ }^{67}$, o de modo tácito como pudieran ser los delitos contra la hacienda pública ${ }^{68}$ o la seguridad vial ${ }^{69}$.

${ }^{64}$ Ver supra.

${ }^{65}$ Feijoo Sánchez, B. (2007), Normativización del Derecho penal y realidad social, Bogotá, Universidad Externado de Colombia, pág. 205.

${ }_{66}$ En profundidad, sobre esta figura, cfr. Silva Días, A. (2003), « ¿Y si todos lo hiciéramos? Consideraciones acerca de la «(in)capacidad de resonancia» del Derecho penal con la figura de la acumulación», $A D P C P$, tomo LVI, págs. 433 y sig.; y Fuentes Osorio, J.L. (2006), «Formas de anticipación de la tutela penal», RECPC, 08-08, págs. $25 \mathrm{y}$ sig.

67 Cfr. arts. 325 y 326 que castigan la realización de las acciones descritas cuando se realicen por sí mismas o conjuntamente con otras.

${ }^{68}$ Así, por ejemplo, el art. 305 señala que «1. El que, por acción u omisión, defraude a la Hacienda Pública estatal, autonómica, foral o local, eludiendo el pago de tributos, cantidades retenidas o que se hubieran debido retener o ingresos a cuenta, obteniendo indebidamente devoluciones o disfrutando beneficios fiscales de la misma forma, siempre que la cuantía de la cuota defraudada, el importe no ingresado de las retenciones o ingresos a cuenta o de las devoluciones o beneficios fiscales indebidamente obtenidos o disfrutados exceda de ciento veinte mil euros será castigado con la pena de prisión de uno a cinco años y multa del tanto al séxtuplo de la citada cuantía, salvo que hubiere regularizado su situación tributaria en los términos del apartado 4 del presente artículo».

${ }^{69}$ Cfr. art. 379 que castiga a quien "condujere un vehículo de motor o un ciclomotor a velocidad superior en sesenta kilómetros por hora en vía urbana o en ochenta kilómetros por hora en vía interurbana a la permitida reglamentariamente» 
La presencia de conductas de daño cumulativo, propias de la administración, carece de legitimación en el Derecho penal por suponer una vulneración del principio de culpabilidad y del de ofensividad. El castigo de estos comportamientos, inocuos por sí mismos, obedece a la premisa de "¿y si todos lo hiciéramos?" presente en el ámbito sancionador de la Administración.

Los sujetos no responderían así por su propia conducta lesiva para el bien jurídico sino por la posibilidad de una hipotética lesión por las conductas cometidas por terceros ${ }^{70}$.

Este camino que hace tiempo emprendió el Derecho penal hacia formas administrativas de racionalidad supone su degradación a sectores inferiores del ordenamiento jurídico en cuanto a tutela del individuo se refiere. En este sentido, podría afirmarse que la introducción del castigo de la mera actividad, de la desobediencia, supone una renuncia a su propia finalidad de protección de bienes jurídicos cuando no encuentra ninguna referencia a la lesividad de los mismos.

Conviene recordar en este punto que el ius puniendi no debe considerarse como un derecho subjetivo estatal, puesto que entonces carecería de sentido la existencia de los diversos bienes jurídicos; todas las conductas criminales atentarían ese único bien jurídico ius puniendi que es el de desobediencia hacia la legítima regulación de la vida en sociedad encomendada al Estado ${ }^{71}$. El refuerzo del cumplimiento de las funciones estatales deberá venir de la mano del Derecho administrativo, seleccionando el Derecho pe-

${ }^{70}$ En este sentido, Carnevali Rodríguez, S. (2000), "Algunas reflexiones en relación a la protección penal de los bienes jurídicos supraindividuales», Revista Chilena de Derecho, vol. 27, núm. 1, pág. 145. Como lo expone Silva Sánchez, «tal pregunta (puramente genérica, estadística) adquiere todo su sentido desde perspectivas de gestión de un determinado sector, sea éste el del tráfico rodado o el de la evacuación de los residuos. Pero es inadmisible como criterio para la imputación penal de responsabilidad a un determinado sujeto por el concreto significado de la conducta aislada que ha realizado; pues una sanción así fundamentada no deja de ser, desde la perspectiva del Derecho penal, una sanción "ex iniuria tertii". No hay en ella ninguna posibilidad de introducir elementos de lesividad concreta: ni lesión, ni peligro concreto, ni peligro abstracto entendido como peligro realmente existente, constatable en la conducta en virtud de un juicio ex ante. Simplemente, peligro presunto, peligro estadístico o - todavía mejor - peligro global». En Silva Sánchez, J.M. (1999), cit., págs. 104-105. En el mismo sentido, Feijoo Sánchez, B., (2007), cit., págs. 204 y sig.; y Torio López, A. (1991), «Injusto penal e injusto administrativo (presupuestos para la reforma del sistema de aranceles)», en Martín-Retortillo Baquer, S., Estudios sobre la Constitución española: Homenaje al profesor Eduardo García de Enterría, vol. 3, Madrid, Civitas, págs. 2529-2546.

${ }_{71}$ Zaffaroni, E.R., Tratado de Derecho penal. Parte general. Tomo I, Buenos Aires, Ediar, 1998, pág. 33. 
nal, en su caso, las modalidades de ataque más grave atentatorias contra sectores indispensables para el mantenimiento de la vida en sociedad.

En este sentido, no encuentra legitimación el castigo de conductas fundadas en el mero incumplimiento de obligaciones administrativas. La ausencia de permisos, autorizaciones $\mathrm{u}$ otras formalidades podrá ser considerada, en su caso, un elemento más a evaluar por el juez para la determinación de la culpabilidad siempre que se acompañe de otros elementos fácticos que determinen la gravedad - peligrosidad- de la conducta, pero nunca el elemento determinante para el castigo.

Así, no superarían este parámetro el citado art. $326.2 \mathrm{CP}^{72}$; las agravantes contempladas en las letras a), b), c) y d) del art. $327 \mathrm{CP}^{73}$ fundadas en una presunción de que el incumplimiento de las obligaciones administrativas supone una mayor peligrosidad para el bien jurídico; y el art. $360 \mathrm{CP}^{74}$ por castigar de igual modo el amplio abanico de formalidades contenidas en todas las leyes y reglamentos del sector, siendo algunas completamente inocuas para el interés tutelado.

72 "Quien, fuera del supuesto a que se refiere el apartado anterior, traslade una cantidad no desdeñable de residuos, tanto en el caso de uno como en el de varios traslados que aparezcan vinculados, en alguno de los supuestos a que se refiere el Derecho de la Unión Europea relativo a los traslados de residuos, será castigado con una pena de tres meses a un año de prisión, o multa de seis a dieciocho meses e inhabilitación especial para profesión u oficio por tiempo de tres meses a un año».

${ }^{73} \mathrm{El}$ art. 327 agrava la pena en los siguientes supuestos: «a) Que la industria o actividad funcione clandestinamente, sin haber obtenido la preceptiva autorización o aprobación administrativa de sus instalaciones; $b$ ) Que se hayan desobedecido las órdenes expresas de la autoridad administrativa de corrección o suspensión de las actividades tipificadas en el artículo anterior; c) Que se haya falseado u ocultado información sobre los aspectos ambientales de la misma; d) Que se haya obstaculizado la actividad inspectora de la Administración; e) Que se haya producido un riesgo de deterioro irreversible o catastrófico; f) Que se produzca una extracción ilegal de aguas en período de restricciones».

${ }^{74}$ Según el art. 360, "El que, hallándose autorizado para el tráfico de las sustancias o productos a que se refiere el artículo anterior, los despache o suministre sin cumplir con las formalidades previstas en las Leyes y Reglamentos respectivos, será castigado con la pena de multa de seis a doce meses e inhabilitación para la profesión $u$ oficio de seis meses a dos años». 


\section{V.3. La ciencia y la imprudencia}

Suele ser habitual que, junto a delitos de peligro, el legislador introduzca formas imprudentes de comisión ${ }^{75}$, lo que no deja de resultar paradójico si se atiende al origen de estas figuras.

Como lo expone Quintero Olivares ${ }^{76}$, de no existir los delitos de peligro, las conductas que estos contemplan no podrían ser castigadas puesto que, a lo sumo, suponen la comisión de otros delitos - homicidio, lesión, daños, etc.- en grado de tentativa. Al faltar el elemento intencional - puesto que sino se procedería a dicho castigo-, las conductas deben quedar impunes. Así, los delitos de peligro no son más que actividades cuyos autores realizan con culpa consciente o inconsciente - es discutible la presencia de dolo eventual- que, por una decisión político criminal, se castigan de modo autónomo.

Este castigo independiente supone su conversión en delitos dolosos - dolo de peligro, como se ha denominado- y la introducción de una nueva modalidad de imprudencia de una situación hipotéticamente peligrosa para el bien jurídico protegido ${ }^{77}$. Como puede advertirse, la lejanía con la efectiva lesión resulta cada vez mayor.

Las implicaciones más relevantes, no obstante, guardan relación con la imputación objetiva de conductas por lo que su exposición tendrá lugar al tratar los problemas estructurales del modelo de tipificación optado por el legislador, en el epígrafe siguiente.

\section{PROBLEMAS ESTRUCTURALES DEL MODELO DE TIPIFICACIÓN ADOPTADO}

Este modelo que el legislador penal ha adoptado, como se ha visto, supone la cesión de amplios espacios de decisión a la administración y, por ende, al ámbito científico. El principio de precaución no es sino el modo que encontraron los gobiernos para acercarse a

${ }^{75}$ Así, art. 159.2 para el delito de manipulación genética; art. 331 para los delitos contra el medioambiente; art. 344 para los delitos relativos a la energía nuclear; y el art. 367 para los delitos contra la salud.

${ }^{76}$ Quintero Olivares, G. (2003), cit., págs. 246 y sig.

77 Sobre la relación entre la imprudencia y el peligro, cfr. Romeo Casabona, C.M. (2005), Conducta peligrosa e impudencia en la sociedad de riesgo, Granada, Comares. 
la actividad científica, procurando reducir la incertidumbre que se genera en torno a su desarrollo.

En materia penal, no obstante, la asunción de este principio no supone más que la renuncia a buscar soluciones óptimas de control de las actividades peligrosas, puesto que los caracteres que de esta regulación se desprenden evitan la pronunciación sobre los problemas de fondo.

En efecto, el empleo de delitos de peligro supone una relajación de los criterios de imputación de las conductas que guarda relación con tres aspectos fundamentales de la atribuibilidad.

En primer lugar, porque la incertidumbre que rodea la actividad científica pone en duda que los sujetos puedan prever o anticipar en todos los casos los posibles efectos lesivos de su conducta, por lo que no sería posible su castigo culposo ${ }^{78}$. Como señala Galán, "¿cómo se va a poder reprochar al que efectúe una conducta que nunca se hubiese realizado anteriormente y sobre cuyos posibles efectos adversos ni siquiera los mayores expertos en la materia habian podido ponerse de acuerdo, que su ejecución, una vez realizada, se materialice en algún resultado lesivo? ¿Realmente se puede tener su conducta por negligente $y$, consecuentemente, se le puede hacer responsable de la producción de dicho resultado, aunque no lo hubiese podido prever? ¿O, en realidad, le estamos sancionando y haciendo responsable de forma completamente objetiva y sin culpa por la mera generación de dichos resultados, estableciendo asi una suerte de responsabilidad objetiva por el producto completamente incompatible con el principio de culpabilidad?» ${ }^{79}$.

En segundo lugar, se debe considerar que esa misma incertidumbre dificulta en ocasiones el establecimiento del nexo causal entre la conducta y los daños imputados ${ }^{80}$. Así, en diversos supuestos los tribunales han encontrado numerosos problemas a la hora de establecer la causalidad por no existir leyes científicas a las que poder acudir, agravados por la aportación de informes periciales contradictorios por las partes del proceso.

${ }^{78}$ Romeo Casabona, C.M. (2004), cit.; Mendoza Buego, B. (2004) cit.; y Escobar Vélez, S. (2012), La responsabilidad penal por productos defectuosos, Valencia, Tirant lo Blanch, págs. 74 y sig.

${ }^{79}$ Galán Muñoz, A. (2015), cit., pág. 78.

${ }^{80}$ En profundidad, de la Cuesta Aguado, P.M. (1999), Causalidad en los delitos contra el medio ambiente, 2. ${ }^{\mathrm{a}}$ ed., Valencia, Tirant lo Blanch; y Fierro, G.J. (2002), cit. 
Casos como Lederspray ${ }^{81}$, Holzschutzmittel ${ }^{82}$ y Contergan $^{83}$, en Alemania, de la fábrica de aluminio Montecatini-Edison di Mori ${ }^{84}$, en Italia, o del aceite de colza ${ }^{85}$ en España ${ }^{86}$ han ido sentado las bases para la consolidación de una línea jurisprudencial de dudoso encaje en un Derecho penal garantista por rebajar los criterios tradicionalmente exigidos para la imputación de conductas.

Así, en el caso del citado aceite de colza ${ }^{87}$, no había certeza pero sí sospechas de que, como consecuencia de la incorporación de de-

${ }^{81}$ Se trata de un spray protector de cuero que prácticamente desde el inicio de su comercialización, en la década de 1960, ocasionó diversos problemas para la salud de los usuarios tales como fiebre, problemas respiratorios, tos, edemas de plumón, etc. Pese a la adopción de medidas por parte de la empresa productora - consistentes en la sustitución de la materia prima-, los daños prosiguieron sin que la relación causal con el producto se halle del todo clara. En este sentido, el producto no sería retirado del mercado sino que bastó con añadir una advertencia sobre su toxicidad en el etiquetado.

${ }^{82}$ De modo idéntico que el supuesto anterior, la utilización de este limpiador de madera ocasionó diversos daños en las personas sin que en un primer momento pudiera establecerse con claridad la relación con el producto. Pese a que este obstáculo fue salvado, la discusión posterior se centró en determinar si los daños podían ser producidos por el contacto con pequeñas dosis del producto.

${ }^{83}$ Se trata de un medicamento recetado a embarazadas con cuadros depresivos cuyo principal compuesto, la talidomina, produjo alteraciones en el sistema nervioso y, en numerosos casos, malformaciones en el feto.

${ }^{84}$ En 1929, en las proximidades de la citada fábrica, comenzaron a detectarse daños en cultivos que al poco tiempo se extendieron al ganado y a las personas a modo de manifestaciones cutáneas de tipo epidémico. Tras el cierre de la misma y la adopción de medidas de seguridad, las manifestaciones resurgieron en 1964, coincidiendo con el funcionamiento de una nueva sección de la fábrica.

${ }^{85}$ Ver, infra.

${ }^{86}$ En general, sobre estos casos, Hassemer, W. y Muñoz Conde, F. (1995), La responsabilidad por el producto en derecho penal, Valencia, Tirant lo Blanch, págs. 87 y sig. y 129 y sig; Rodríguez Montañés, T. y Paredes Castañón, J.M. (1995): El caso colza: responsabilidad penal por productos adulterados o defectuosos, Valencia, Tirant lo Blanch, págs. 30 y sig.; Donna, E. (2010), «Imputación y ciencia penal», en Romeo Casabona, C.M. y Sánchez Lázaro, F.G. (eds.), cit., págs. 204 y sig.; Galán Muñoz, A. (2015), cit., pág. 73; Paredes Castañón, J.M. (1994), «Límites de la responsabilidad penal individual en supuestos de comercialización de productos defectuosos: algunas observaciones acerca del "caso de la colza" », PJ, núm. 33, págs. 421 y sig.; del mismo autor (1996), "Problemas de la responsabilidad penal en supuestos de comercialización de productos adulterados: algunas observaciones acerca del 'caso de la colza'» en Mir Puig, S. y Luzón Peña, D.M. (coords.), Responsabilidad penal de las empresas y sus órganos y responsabilidad por el producto, págs. 289310; Rodríguez Montañés, T. (1996), «Problemas de responsabilidad penal por comercialización de productos adulterados: algunas observaciones acerca del «caso de la colza» (Primera parte)», en Mir Puig, S. y Luzón Peña, D.M. (coords.), cit., págs. 263-287; y Jiménez Aparicio, E. (2003), «La ejecución de la sentencia de la colza», InDret, enero.

${ }^{87}$ El AAN de 12 de abril de 1984 dividiría el caso en dos procesos diferentes. El «de los aceiteros», que daría lugar a la SAN de 20 de mayo de 1989, recurrida ante 
terminadas sustancias -entre las que se encontraba el aceite de colza desnaturalizado, no apto para el consumo- al aceite destinado al consumo humano, se originó lo que en un primer momento vino a denominarse "síndrome tóxico" que supuso la producción de una serie de lesiones graves y la muerte de más de 300 personas $^{88}$.

En base a diversos estudios epidemiológicos, no concluyentes de por sí, y sin conocer con exactitud el agente causante del daño ni su funcionamiento, el Tribunal Supremo confirmaría la condena de la Audiencia Nacional entendiendo que "para la determinación de una ley causal natural, al menos en el sentido de derecho penal..., no es necesario... que se haya podido conocer el mecanismo preciso de producción del resultado (en este caso la toxina que ha producido los resultados típicos) en tanto se haya comprobado una correlación o asociación de los sucesos relevantes y sea posible descartar otras causas que hayan podido producir el mismo» 89 .

Sigue para esto la fundamentación de los mencionados casos alemanes de Lederspray ${ }^{90}$ y Contergan ${ }^{91}$, entendiendo que en los su-

el Supremo (STS de 23 de abril de 1992), y el «de los cargos de la Administración», que concluye mediante la SAN de 24 de mayo de 1996 y, en recurso, con la STS de 26 de septiembre de 1997. En profundidad, Jiménez Aparicio, E. (2003), cit.

88 Señala Gómez Rivero que las 300 muertes iniciales en 1981, cuando el suceso tuvo lugar, ascendieron a 700 en 1995, según los medio de comunicación. En Gómez Rivero, M.C. (2010), "Causalidad, incertidumbre científica y resultados a largo plazo», en Romeo Casabona, C.M. y Sánchez Lázaro, F.G. (eds.), cit., pág. 172.

89 STS de 23 de abril de 1992.

90 "En este sentido, el Tribunal Supremo Alemán (BGH) ha sostenido en una reciente S. 6-7-1990, conformatoria en este aspecto de una decisión del Landgericht Mainz (Tribunal de Maguncia) (caso "Erdal» o "Lederspray»), que "si se ha comprobado de una manera jurídicamente inobjetable que la composición del contenido de un producto - aunque no sea posible una mayor aclaración-es causante de los daños, no será requisito para la prueba de la causalidad que además se compruebe por qué dicho producto pudo ser causal de los daños, es decir, cuál ha sido según un análisis y los conocimientos científico-naturales el fundamento último de esa causalidad». Sin embargo, se ha exigido que, en el caso en el que la causalidad no se pueda determinar de esta manera, o sea, de acuerdo con métodos y conocimientos científico-naturales, el desarrollo del mecanismo causal, los tribunales «tendrán que haber podido excluir toda otra causa del daño que entre en consideración mediante una ponderación de la prueba jurídicamente inobjetable».

Desde esta perspectiva «el nexo causal entre la composición de un producto y el daño a la salud de sus consumidores se debe considerar comprobado de manera jurídicamente inobjetable, aunque quede abierta la cuestión de cuál es la sustancia que ha desencadenado los daños, siempre y cuando quepa excluir otras causas de éstos que entren en consideración».»

${ }^{91}$ Afirma el Tribunal que "sobre estas bases el Tribunal de Aquisgrán concluyó que "para la prueba de la causalidad carece de influencia que el mecanismo causal de la Thalidomida (...) en particular no sea conocido» 
puestos de cursos causales no verificables ${ }^{92}$ la certeza en Derecho se alcanza de modo distinto a la del ámbito científico natural. Como afirmara en la STS núm. 693/1986, de 12 de mayo, «la demostración propia del Derecho... (es) distinta de la científico-natural, en tanto no supone una certeza matemática y una verificabilidad excluyente de la posibilidad de lo contrario, sino simplemente la obtención de una certidumbre subjetiva».

Esa certidumbre subjetiva se basa en este caso en una causalidad probabilística o estadística propia de la física y las matemáticas. Como lo expone Romeo Casabona, "lo que hace que 'c' cuente como causa de 'e' es que la ocurrencia de 'c' aumente la probabilidad objetiva de la ocurrencia de 'e'»" ${ }^{93}$. Así, "mientras que las explicaciones causales deterministas son tenidas como leyes necesarias y excluyentes de toda clase de hipótesis, las explicaciones causales probabilistas parten de la concurrencia de un número de variables cuantitativamente elevadas, que se conocen como ámbitos "indeterminados" ${ }^{94}$.

Pese a que esta argumentación se aleja mucho de ser unánimemente aceptada ${ }^{95}$, los tribunales distinguen la causalidad científica de la jurídica, intentado no obviar las leyes de la naturaleza sino, como se verá más adelante, interpretarlas conforme a sus propias necesidades.

Finalmente, el tercer problema al que se hacía referencia se halla íntimamente ligado al anterior y es el relativo al ámbito probatorio de estas actividades. Existen serias dificultades, como es lógico, a la hora de aportar pruebas de la existencia de esa causalidad que ya de por sí es difícil de determinar; incluso en ocasiones se hace difícil

92 Ver Torio López, A. (1983), «Cursos causales no verificables en Derecho penal», APDCP, tomo XXXVI, II, págs. 221-238.

93 Romeo Casabona, C.M. (2010), "Conocimiento científico y causalidad en Derecho penal», en Romeo Casabona, C.M. y Sánchez Lázaro, F.G. (eds.), cit., pág. 124.

${ }^{94}$ Ibídem.

95 Cfr. Romeo Casabona, C.M. (2010), cit., y bibliografía allí citada. Como señala Tanus "las hipótesis científicas se comprueban y asumen la forma de "leyes probabilísticas" insertadas en una teoría científica corroborada, éstas podrán ser asumibles con base en atribuciones de causalidad general, pero no en el plano de causalidad individual. Sin embargo, una observación o estudio que todavía no haya sido confirmado y compartido por la comunidad científica internacional no posee el status de ley científica' $y$, de este modo, no puede inducir a la modificación de las estrategias empresariales; frente a un riesgo desconocido nada puede ser exigible, es decir, ninguna regla cautelar es válida porque no puede ser formulada», en Tanus Job e Meira, B. (2009), La intervención del derecho penal en materia de bioseguridad. La criminalización de la actividad empresarial biotecnológica de liberación intencional en el ambiente con fines comerciales y de comercialización de productos biotech, Tesis doctoral, Universidad de Salamanca, pág. 338. 
acreditar la existencia de daños dado que el equipamiento especial que se requiere para la detección de consecuencias lesivas para el medioambiente o relacionadas con la detección de actividad nuclear o radioactiva no está al alcance de cualquiera ${ }^{96}$.

De este modo, como se ha comentado, el empleo del trinomio regulador evita al legislador pronunciarse sobre el fondo del asunto ya que con la anticipación no ha de llegar a los problemas de atribuibilidad que se originan en torno a la actividad científica. Mediante el recurso a los delitos de peligro asociados a remisiones legislativas y el castigo de la imprudencia, los criterios de reproche penal se suavizan puesto que ya no es necesario probar la intencionalidad de las conductas realmente lesivas sino, a lo sumo, el denominado dolo de peligro asociado en muchos casos al incumplimiento de la normativa extrapenal. Pero, dado que hablamos de una criminalidad fundamentalmente culposa ${ }^{97}$, la previsión de esta modalidad delictiva viene a llenar cualquier posible espacio de impunidad debido a la falta de previsión.

Los delitos de peligro $-\mathrm{y}$ fundamentalmente lo de mera activi$\mathrm{dad}^{98}$ - tampoco requieren probar los daños imputados o establecer con exactitud el nexo causal entre la conducta y el resultado lesivo. La anticipación hace que, en su caso, haya que probar la potencialidad lesiva de la conducta lo que, sin dudas, presenta mayores facilidades dado el entorno científico en el que se mueven estas actividades. Pero estas exigencias se suavizan incluso en los delitos de peligro abstracto ya que la mera realización de la conducta o el incumplimiento de determinadas obligaciones presuponen su peligrosidad.

96 En profundidad, cfr. de la Cuesta Aguado, P.M. (2011), «Lección 34. a. Delitos relativos a la energía nuclear y radiaciones ionizantes», en Álvarez García, F.J. (dir.), Derecho penal español. Parte especial (II), Valencia, Tirant lo Blanch, págs. 1119-1149 y bibliografía allí citada.

${ }_{97}$ Sobre la característica no intencional de esta nueva delincuencia, Silva Sánchez, J.M. (1999), cit., pág. 22, y Suárez González, C.J. (2003), «Derecho penal y riesgos tecnológicos», en Arroyo Zapatero, L., Neumann, U. y Nieto Martín, A. (coords.), cit., pág. 289-297.

98 Benítez Ortúzar, B.F. (2013), «Los fraudes alimentarios nocivos realizados por productores, distribuidores y comerciantes», en Suárez López, J.M. (coord.) y Morillas Cueva, L. (dir.), Derecho y consumo: aspectos penales, civiles y administrativos, págs. 387-438. 


\section{VI.1. Sobre la autonomía del Derecho}

En casos como los anteriormente expuestos - v.gr. el caso del aceite de colza-, se pone de manifiesto el esfuerzo doctrinal por resaltar la autonomía del Derecho con respecto a otras áreas científicas. La autonomía del Derecho supone que no debe verse sometido a los dictámenes de otras áreas, lo que no impide, como es lógico, que acuda a estas de un modo auxiliar para fundamentar sus posteriores construcciones.

En este sentido, el Derecho no podrá oponerse a los hallazgos de otras disciplinas pero sí podrá limitarlos en atención a las necesidades propias o, simplemente, ignorarlos cuando no le aporten la información necesaria para resolver el conflicto, como ha ocurrido en los citados casos.

Cuando el mecanismo de causalidad no pueda determinarse con certeza absoluta porque el estado del conocimiento lo impida, el Derecho debe desarrollar sus propias vías de resolución ya que la realización de justicia no puede aplazarse hasta que la ciencia progrese.

En este sentido, la teoría de la imputación objetiva adquiere especial relevancia al tratarse de áreas donde la determinación del riesgo permitido es fundamental para determinar la posible responsabilidad penal. Así, como señala Larrauri ${ }^{99}$, se trata de casos caracterizados por: a) una actuación incorrecta del sujeto activo; b) la constatación de la lesión del bien jurídico; y c) la imposibilidad de determinar de modo absoluto el nexo causal.

Como es sabido, la imputación vendrá determinada por haber creado el sujeto un riesgo jurídicamente no permitido que se haya realizado en un resultado lesivo para el bien jurídico y, siguiendo a $\operatorname{Roxin}^{100}$, que se halle dentro de la esfera de protección de la norma.

Existen, no obstante, dos cuestiones de difícil solución que son las anteriormente señaladas en relación a la causalidad y a las posibilidades reales de representación de los daños que tienen los sujetos desde una perspectiva ex ante.

En el primer caso, cuando la ciencia no pueda arrojar luz al respecto, habrá que alejarse del concepto de certeza absoluta - objetivamente imposible de alcanzar en todos los casos- sustituyéndolo por una certeza suficiente desde un punto de vista medio. Es decir,

99 Larrauri Pijoan, E. (1988), «Introducción a la imputación objetiva», Estudios penales y criminológicos, núm. 12, 1987-1988, págs. 220-248.

100 Roxin C. (1997), cit., págs. 342 y sig. 
del mismo modo que anteriormente se ha negado la imposibilidad - e irrelevancia - de hallar verdades absolutas, el convencimiento de la existencia de la relación de causalidad deberá ser lo suficientemente fuerte situándonos desde un punto intermedio, sin que sean exigibles los conocimientos exhaustivos de otras disciplinas para fundamentar dicha relación.

En el mismo sentido, en lo que respecta a la segunda cuestión planteada, las posibilidades de representación de los riesgos que sus conductas conllevan vendrán determinadas por la vulneración de las normas de cuidado, especialmente exigibles en caso de tratarse de un profesional o una actividad especial riesgosa. En los supuestos aquí tratados, como se ha comentado, la proliferación de remisiones extrapenales facilita esta labor ya que se cuenta con una referencia concreta a la que acudir. Ahora bien, no toda vulneración de dichas normas puede suponer la exigencia de responsabilidad penal, sino la que guarda relación con los aspectos más relevantes para la tutela del bien jurídico.

Así, siguiendo a Kindhäuser, con carácter previo habrá que determinar las posibilidades reales de previsión que el autor $-\mathrm{y}$ no una figura indeterminada - tenía. Sólo aclarada esta cuestión procederá el análisis de los demás elementos del injusto puesto que las normas especiales de cuidado variarán en atención al primer elemento. Como lo expone el autor, la imputación objetiva ya que no puede establecerse "sin considerar el saber individual del autor, qué medidas son adecuadas al cuidado esperado para la evitación de la realización típica, entonces, en primer lugar, el conocimiento del autor tiene que ser ya un elemento del tipo en la construcción del hecho punible, así como, en segundo lugar, la infracción individual del estándar de cuidado tiene que ser el criterio equivalente al dolo en la constitución del injusto de la acción imprudente» ${ }^{101}$.

Pese a lo adecuada que se entiende que es la introducción de las normas penales en blanco en estos casos por dotar de mayor objetividad la labor del penalista, no conviene olvidar que en determinados supuestos - si bien en una proporción mínima- puede conducir a situaciones injustas. Así, por ejemplo, cuando pese a haber cumplido con todas las formalidades prescritas por las leyes no pueda descartarse el carácter lesivo de la conducta ni su conoci-

101 Kindhäuser, U. (2008), «El tipo subjetivo en la construcción del delito. Una crítica a la teoría de la imputación objetiva», InDret, octubre, págs. 23-24. 
miento por parte del autor ${ }^{102}$, habrá que dictaminar la absolución aun siendo conductas dolosas, siquiera en un grado eventual.

En cualquier caso, se trata de supuestos minoritarios que remiten a problemas a resolver en sede legislativa en las concretas áreas reguladoras del sector, sin que pueda rechazarse el plus de seguridad que aporta condicionar la intervención penal a la previa vulneración de dichas normas.

\section{CRITERIOS DE TIPIFICACIÓN E INTERPRETACIÓN}

Así como anteriormente se ha criticado negativamente el acercamiento al ámbito administrativo para reinterpretar las estructuras básicas y, en cierto sentido, la propia función del Derecho penal, no puede mantenerse la misma postura a la hora de dotar los preceptos de contenido. Antes, al contrario, ha de defenderse un predominio científico en la tipificación e interpretación de delitos que guarden una relación cercana con la normativa administrativa reguladora de cada sector.

Esto supone afirmar que no puede relegarse a la ciencia la decisión, pero sí la explicación de los fenómenos porque, como se viene repitiendo a lo largo de todo este trabajo, los objetivos científicosnaturales difieren en gran medida de los perseguidos por el Derecho. Mientras que allí se pretende incrementar el conocimiento mediante la búsqueda de la verdad, en el ámbito jurídico se quiere posibilitar la coexistencia pacífica en sociedad evitando el caos y las situaciones de injusticia.

En este sentido, la comunicación del legislador y los intérpretes con la normativa extrapenal deberá ser fluida y de permanente actualización dado que no existe otro medio más efectivo de conocer el

102 En el supuesto ejemplificado por Cancio Meliá, "el empresario Mr. E dedica gran parte de su tiempo libre a la biología marina, habiendo alcanzado incluso el grado de doctor en biología. Al inaugurar Mr. E una nueva planta de producción de celulosa de su propiedad, situada en la ribera de un río, el Dr. E piensa fugazmente en que la población de cangrejos fluviales irremediablemente desaparecerá por efecto de los vertidos de la nueva fábrica. En efecto, al cabo de unos meses, los cangrejos prácticamente han desaparecido, lo que afecta muy gravemente al equilibrio del sistema ecológico de la fauna del río en su conjunto, como constata consternado el Dr. E. Sin embargo, Mr. E previamente había solicitado y obtenido de modo plenamente acorde con las disposiciones legales y reglamentarias los pertinentes permisos para iniciar la nueva actividad industrial», en Cancio Meliá, M. (2005), "Aproximación a la Teoría de la Imputación Objetiva», en Bolaños González, M. (comp.), Imputación objetiva y dogmática penal, Mérida, Universidad de Los Andes, pág. 88 págs. 87-122

(C) UNED. Revista de Derecho UNED, núm. 23, 2018 
potencial lesivo de las conductas que mediante el empleo de la regulación especializada fruto del estudio sectorial de las diversas actividades científicas.

De este modo, es preciso que, en la medida de lo posible, la legislación penal emplee los mismos términos que la extrapenal ya que de este modo se remitirá a una realidad concreta, a conceptos que cobran pleno sentido en el entorno científico donde tienen lugar y los artificios interpretativos que tratan de comprender qué es exactamente lo que se pretende prohibir se reducirán al mínimo. El legislador debe renunciar a la invención legislativa, y abstenerse de introducir una suerte de sinónimos entre las acciones punibles ya que este temor a que alguna conducta lesiva para el bien tutelado quede fuera de la ley sólo supone añadir confusión a unos delitos que, de por sí, pueden ser de difícil interpretación.

Así, por ejemplo, los arts. 325, 326, 361 y 362bis contienen un gran número de conductas que presentan un grado de ofensividad distinto para el bien jurídico pero con un marco penal reducido por lo que los márgenes de actuación para el juez se ven muy limitados. En otros casos, la similitud de conductas requiere grandes esfuerzos interpretativos para distinguir lo que, en un primer momento, pareciera tratarse de sinónimos.

Otro ejemplo paradigmático es el caso de los delitos de manipulación genética. Si bien no han sido nunca aplicados ${ }^{103}$, suscitan problemas ${ }^{104}$ a nivel interpretativo por la introducción de conceptos vulgares que no se ajustan del todo a la precisión científica requerida.

En relación al art. $159 \mathrm{CP}$, la alteración del genotipo que no se realice por manipulación — posible, por ejemplo, mediante radiación- queda fuera del precepto teniendo la misma lesividad para el bien jurídico. Asimismo, resulta impreciso qué taras o enfermedades han de considerarse de tal gravedad que excluyan la tipicidad, o a qué concepto de gen se está haciendo referencia ${ }^{105}$.

${ }^{103} \mathrm{El}$ art. 159 sólo ha sido considerado por la AP de Barcelona en el Auto de 13 de octubre de 2008 para desestimar la denuncia realizada contra los estudios que sobre genética se estaban realizando en el ámbito universitario.

104 Son numerosas las críticas por diversos aspectos entre los que destaca el no poseer una homogeneidad por falta de un bien jurídico común. Los preceptos del Título V recogen diversas conductas entre las cuales se halla la manipulación genética strictu sensu pese a que el rótulo de dicho título hiciera parecer lo contrario.

105 Su definición no es unánime y ha ido evolucionando a lo largo de la historia. En profundidad, Canteras Zubieta, J.P. (2012), «La evolución del concepto de gen. Biología, ideología y sociobiología», Eikasia, Revista de Filosofía, núm. 83, enero. 
Asimismo, el art. $160 \mathrm{CP}$ recoge una serie de conductas dispares agrupadas no por tutelar un mismo bien jurídico sino por el empleo de la ingeniería genética en su comisión, lo que constituye un error desde el punto de vista sistemático fruto, como se verá con claridad en el próximo capítulo, de la ceguera que el legislador sufre en ocasiones ante la presencia de elementos técnico-científicos.

En el art. 160.1 CP resulta extremadamente confusa la intencionalidad específica asociada a la utilización de la ingeniería genética. Las armas biológicas podría entenderse que constituyen sólo una especie de las armas exterminadoras de la especie humana. Pero incluso este concepto es excesivamente futurista e impreciso. Antes bien, sería recomendable el empleo de términos conocidos que remiten a una realidad y regulación concreta como pudieran ser las armas de destrucción masiva.

Se destaca también lo poco conveniente del empleo del término crear asociado a seres humanos del art. 160.3 CP. Si sustituyéramos a los humanos por cualquier otro organismo vivo - como un huevo, un ratón o una planta-, es muy probable que dicho término no fuera el empleado sino que utilizáramos generar, producir u otro similar. Más bien parecen las reminiscencias religiosas o antropocéntricas las que influyeron en dicha redacción.

Por lo demás, resulta confuso el empleo del término idénticos ya que esa identidad podría estar referida al genotipo, a una secuencia de ADN, etc.

Asimismo, el empleo del término raza en los seres humanos está siendo seriamente cuestionado desde diversos puntos de vista ${ }^{106}$ por lo que llegar a precisar qué elementos suponen una selección de la misma se hace aún más difícil. Si bien podría entenderse que se está haciendo referencia a determinados caracteres fenotípicos, no existe acuerdo en su determinación y prohibirlos en su totalidad resultaría un exceso penal innecesario para la tutela del bien jurídico.

En cualquier caso, en los arts. 159 y 160 subyace el debate en torno a las prácticas eugenésicas orientadas a mejorar la calidad de vida de la especie humana. La prohibición de ciertas manipulacio-

106 Cfr., entre otros, González Morales, A. (1997), «El concepto de "raza” y la estética de la antropología», Ciencias, núm. 45, enero-marzo, págs. 62-68; Rodero E. y Herrera, M. (2000), «El concepto de raza. Un enfoque epistemológico. The breed concept. A epistemological approach», Archivos de zootécnica, vol. 49, núm. 185, págs. 5-16; y Sierra Alfranca, I. (2001), «El concepto de raza: evolución y realidad. The breed concept: evolution and reality», Archivos de zootécnica, vol. 50, núm. 192, págs. 547-564. 
nes en el fenotipo, dada la comentada imprecisión del término selección de la raza puede suponer la imposibilidad de acabar con ciertos fallos genéticos que se han ido arrastrando a lo largo de la evolución de la especie que de por sí no suponen un peligro para la vida de las personas pero sí un inconveniente en la vida diaria de las personas, como podría ser la miopía hereditaria o alguna dolencia leve similar.

\section{CONCLUSIONES}

El Derecho ha evolucionado adaptándose en cada momento a los progresos tecno-científicos y, por ende, sociales. Esta nueva etapa paradigmática supone un nuevo reto en su desarrollo puesto que la actividad científica y el temor que sus posibles nefastas consecuencias conlleva se están introduciendo en la misma concepción del Derecho penal, cambiando el paradigma in dubio pro libertate por in dubio pro securitate y con él derrumbando los principios que cimentaron el mismo nacimiento del Derecho penal como ciencia.

Si el objetivo de la Ciencia es la búsqueda de la verdad, sólo nos podrá resultar útil a la hora de ampliar los conocimientos. Esto es, habrá que acudir a la misma para obtener una explicación exacta del significado que ciertas actividades y fenómenos tienen para el ser humano, evaluar su potencial lesivo y exponer los diversos modos de funcionamiento. Luego, no sólo es recomendable sino que resulta imprescindible que el legislador y el intérprete acudan a la misma a la hora de crear y aplicar los tipos penales, pero siempre, como se ha mencionado, de un modo auxiliar, sin ceder espacios en el ejercicio de sus funciones ni en la adopción de decisiones. Esto es, manteniendo el Derecho su autonomía.

\section{BIBLIOGRAFÍA}

Aguilar, S. y JoRdan, A.J. (2003), «Principio de precaución, políticas públicas y riesgo», Politica y Sociedad, vol. 40, núm. 3, págs. 61-79.

Alonso Álamo, M. (2014), «¿Riesgos no permitidos? Observaciones sobre la incidencia del principio de precaución en el Derecho penal», en Gómez Tomillo, M., cit., edición electrónica sin paginar.

Bacigalupo Zapater, E. (1999), Principios constitucionales de derecho penal, Buenos Aires, Hammurabi.

Beck, U. (1998) Políticas ecológicas en la Edad del Riesgo. Antídotos. La irresponsabilidad organizada, Barcelona, El Roure. 
BECK, U. (2002), La sociedad del riesgo global, Madrid, Siglo XXI de España editores.

BECK, U. (2007), "Vivir en la sociedad del riesgo mundial. Living in the World Risk Society», Dinámicas interculturales, núm. 8, Barcelona.

BELtRÁN GaRCÍA-EchÁNIZ, A. (2010), «El desarrollo de la política científica y tecnológica en España», en Romeo Casabona, C.M. y Sánchez Lázaro, F.G. (eds.), La adaptación del Derecho penal al desarrollo social y tecnológico, Granada, Comares, págs. 3-23.

Benítez ORTúzAR, B.F. (2013), «Los fraudes alimentarios nocivos realizados por productores, distribuidores y comerciantes», en Suárez López, J.M. (coord.) y Morillas Cueva, L. (dir.), Derecho y consumo: aspectos penales, civiles y administrativos, págs. 387-438.

Bonamigo, E.L, (2010), El principio de precaución: un nuevo principio bioético y biojurídico, Tesis doctoral, Universidad Rey Juan Carlos.

CAMPIONE, R. (2003), «El que algo quiere algo le cuesta: notas sobre la killateralschädengesellschaft», en Da Agra, C. et al., La seguridad en la sociedad del riesgo. Un debate abierto, Barcelona, Atelier.

Cancio Melí́, M. (2005), «Aproximación a la Teoría de la Imputación Objetiva», en Bolaños González, M. (comp.), Imputación objetiva y dogmática penal, Mérida, Universidad de Los Andes, pág. 88 págs. 87-122.

Canteras Zubieta, J.P. (2012), «La evolución del concepto de gen. Biología, ideología y sociobiología», Eikasia, Revista de Filosofía, núm. 83, enero.

CARneVali Rodríguez, S. (2000), «Algunas reflexiones en relación a la protección penal de los bienes jurídicos supraindividuales», Revista Chilena de Derecho, vol. 27, núm. 1.

CAstaldo, A. (1997), «La concreción del 'riesgo jurídicamente relevante'», en Silva Sánchez, J.M. (ed.), Política criminal y nuevo Derecho penal. Libro homenaje a Claus Roxin, Barcelona, José María Bosch ed., págs. 233-242.

Cierco SeIRA, C. (2004), «El principio de precaución: reflexiones sobre su contenido y alcance en los derechos comunitario Y español», Revista de Administración Pública, núm. 163, págs. 73125.

Cruz Bottini, P. (2007), "Principio de precaución, Derecho penal y sociedad de riesgos», Revista General de Derecho penal, núm. 7. 
De la Cuesta Aguado, P.M. (1999), Causalidad en los delitos contra el medio ambiente, 2. ${ }^{\mathrm{a}}$ ed., Valencia, Tirant lo Blanch.

De la Cuesta Aguado, P.M. (2011), «Lección 34. a . Delitos relativos a la energía nuclear y radiaciones ionizantes», en Álvarez García, F.J. (dir.), Derecho penal español. Parte especial (II), Valencia, Tirant lo Blanch, págs. 1119-1149.

De Vicente Martínez, R. (2004), El principio de legalidad penal, Valencia, Tirant lo Blanch, edición electrónica sin paginar.

DiEz Ripollés, J.L. (2006), «De la sociedad del riesgo a la seguridad ciudadana un debate desenfocado", en Cancio Meliá, M. y GómezJara Díez, C., Derecho penal del enemigo: el discurso penal de la exclusión, vol. 1, Madrid, Edisofer págs. 553-602.

Donna, E. (2010), «Imputación y ciencia penal», en Romeo Casabona, C.M. y Sánchez Lázaro, F.G. (eds.), cit.

Escobar VÉLEZ, S. (2010), «El traslado del principio de precaución al Derecho penal en España», Revista Nuevo Foro Penal, vol. 6, núm. 75, julio-diciembre, págs. 15-40.

EscobAR VÉLEZ, S. (2012), La responsabilidad penal por productos defectuosos, Valencia, Tirant lo Blanch.

Esteve Pardo, J. (1999), Técnica, riesgo y Derecho. Tratamiento del riesgo tecnológico en el Derecho ambiental, Barcelona, Ariel.

Esteve Pardo, J. (2002), Autorregulación. Génesis y efectos, Cizur Menor, Aranzadi.

Esteve Pardo, J. (2009), El desconcierto del Leviatán. Política y derecho ante las incertidumbres de la ciencia, Madrid, Marcial Pons.

Esteve Pardo, J. y Tejada Palacios, J. (2013), Ciencia y Derecho: la nueva división de poderes, Madrid, Fundación Coloquio jurídico europeo.

FeIJoo SÁnchez, B. (2007), Normativización del Derecho penal y realidad social, Bogotá, Universidad Externado de Colombia.

Fierro, G.J. (2002), Causalidad e imputación, Buenos Aires, Astrea.

FueNTES OsoRIo, J.L. (2006), «Formas de anticipación de la tutela penal», RECPC, 08-08.

GaLÁN MuÑoz, A. (2015), «La problemática utilización del principio de precaución como referente de la política criminal del moderno derecho penal. ¿Hacia un derecho penal del miedo a lo desconocido o hacia uno realmente preventivo? The use of the precau- 
tionary principle as a benchmark of the modern criminal policy in criminal law. Towards a criminal law of fear to unknown or to one really preventive?», REJ-Revista de Estudios de la Justicia, núm. 22, págs. 69-117.

Gómez Rivero, M.C. (2010), "Causalidad, incertidumbre científica y resultados a largo plazo», en Romeo Casabona, C.M. y Sánchez Lázaro, F.G. (eds.), cit.

Gómez Tomillo, M. (2014), Principio de precaución y derecho punitivo del Estado, Tirant lo Blanch, edición electrónica sin paginar.

GonzÁlez Morales, A. (1997), «El concepto de "raza” y la estética de la antropología», Ciencias, núm. 45, enero-marzo, págs. 62-68.

Gracia Martin, L. y Escuchuri Asia, E., (2005), cit.

Habermas, J. (1992), Teoría de la acción comunicativa II. Crítica de la razón funcionalista, Madrid, Taurus,.

Hassemer, W. y MuÑoz Conde, F. (1995), La responsabilidad por el producto en derecho penal, Valencia, Tirant lo Blanch.

HeFENDEHL, R. (2002), «¿Debe ocuparse el derecho penal de riesgos futuros? Bienes jurídicos colectivos y delitos de peligro abstracto", $R E C P C, 04-14$, pág. 4.

Hermitee, M.A. (2007), «Capítulo I. La fundación jurídica de una sociedad de las ciencias y la técnica a través de las crisis y de los riesgos», en Red Latinoamericana y Europea sobre Gobierno de los Riesgos, cit., págs. 13-63.

Herzog, F. (1993), "Límites al control general de los riesgos sociales:(una perspectiva crítica ante el Derecho Penal en peligro)», $A D P C P$, tomo XLVI, I, págs. 319-320.

HormazÁbal Malarée, H. (1992), Bien jurídico y Estado social y democrático de Derecho. El objeto protegido por la norma penal, 2. ${ }^{a}$ ed., Santiago de Chile, Editorial Jurídica ConoSur.

Huerta Tocildo, S. (2001), «Principios básicos del Derecho penal y el art. 325 del Código penal», Revista Penal, núm. 8, págs. 3952.

Jiménez Aparicio, E. (2003), "La ejecución de la sentencia de la colza», InDret, enero.

KINDHÄUSER, U. (2008), «El tipo subjetivo en la construcción del delito. Una crítica a la teoría de la imputación objetiva», InDret, octubre, págs. 23-24. 
LARRAURI PiJOAN, E. (1988), «Introducción a la imputación objetiva», Estudios penales y criminológicos, núm. 12, 1987-1988, págs. 220248.

Martínez PéRez, E. (2014), «El principio de cautela en la práctica internacional y europea: concepto, naturaleza jurídica y contenido», en Gómez Tomillo, M., cit., edición electrónica sin paginar.

Mendoza Buergo, B. (2003), "Gestión del riesgo y política criminal de seguridad en la sociedad del riesgo», en Da Agra, C. et al., La seguridad en la sociedad del riesgo. Un debate abierto, Barcelona, Atelier.

Mendoza Buergo, B. (2004), «Principio de precaución, Derecho penal del riesgo y delitos de peligro», en Romeo Casabona, C.M. (ed.), Principio de precaución, cit., págs. 436-442.

Mir Puig, S. (1989), «Bien jurídico y bien jurídico-penal como límite del ius puniendi», Estudios penales y criminológicos, núm. 14, 1989-1990, págs. 203-216.

Mir Puig, S. (2003), Introducción a las bases del Derecho penal. Concepto y método, 2. ${ }^{\mathrm{a}}$ ed., Buenos Aires, Euro Editores, Montevideo, B de F Ltda..

Moccia, S. (1997), «De la tutela de bienes a la tutela de funciones: entre ilusiones postmodernas y reflujos liberales», en Silva Sánchez, J.M. (ed.), Política criminal..., cit., págs. 113-142.

Montoro Chiner, M.J. (2005), «Perspectivas de contraste ante el riesgo ecológico. Agentes que intervienen en la evaluación del riesgo. En especial, los comités científicos», en Buxó, M.J. y Casado, M. (coords.), Riesgo y precaución. Pasos hacia una bioética ambiental, Barcelona, Residènca d'Investigadors CSIC-Generalitat de Catalunya, págs. 125-136

Paredes Castañón, J.M. (1994), «Límites de la responsabilidad penal individual en supuestos de comercialización de productos defectuosos: algunas observaciones acerca del "caso de la colza" », $P J$, núm. 33, págs. 421 y sig.

Paredes Castañón, J.M. (1995) El riesgo permitido en Derecho Penal (régimen jurídico-penal de las actividades peligrosas), Madrid, Ministerio de Justicia e interior.

Paredes Castañón, J.M. (1996), «Problemas de la responsabilidad penal en supuestos de comercialización de productos adulterados: algunas observaciones acerca del "caso de la colza" » en Mir Puig, S. y Luzón Peña, D.M. (coords.), Responsabilidad penal de las em- 
presas y sus órganos y responsabilidad por el producto, págs. 289310.

Prieto Molinero, R.J. (2005), El riesgo de desarrollo: un supuesto paradójico de la responsabilidad por el producto, Madrid, Dykinson.

Quintero Olivares, G. (2003), «Los delitos de riesgo en la política criminal de nuestro tiempo", en Arroyo Zapatero, L., Neumann, U. y Nieto Martín, A. (coords.), Crítica y justificación del Derecho penal en el cambio de siglo. El análisis crítico de la Escuela de Frankfurt, Cuenca, Universidad de Castilla-La Mancha.

Quintero Olivares, G. (2013), Derecho penal ambiental, Valencia, Tirant lo Blanch.

Rodero E. y Herrera, M. (2000), «El concepto de raza. Un enfoque epistemológico. The breed concept. A epistemological approach», Archivos de zootécnica, vol. 49, núm. 185, págs. 5-16.

RodríGuez Montañés, T. (1996), «Problemas de responsabilidad penal por comercialización de productos adulterados: algunas observaciones acerca del "caso de la colza» (Primera parte)», en Mir Puig, S. y Luzón Peña, D.M. (coords.), cit., págs. 263-287.

Rodríguez Montañés, T. y Paredes Castañón, J.M. (1995): El caso colza: responsabilidad penal por productos adulterados o defectuosos, Valencia, Tirant lo Blanch.

Romeo Casabona, C.M. (2004), «Aportaciones del principio de precaución al Derecho penal», en Romeo Casabona, C.M. (ed.), Principio de precaución, biotecnología y Derecho, Cátedra interuniversitaria Fundación BBVA-Diputación Foral de Bizkaia de Derecho y Genoma Humano- Bilbao-Granada, Comares, págs. 385 y sig.

Romeo Casabona, C.M. (2005), Conducta peligrosa e impudencia en la sociedad de riesgo, Granada, Comares.

Romeo Casabona, C.M. (2010), «Conocimiento científico y causalidad en Derecho penal», en Romeo Casabona, C.M. y Sánchez Lázaro, F.G. (eds.), cit.

Roxin C. (1997), Derecho penal. Parte General. Tomo I. Fundamentos. La estructura de la Teoría del delito, trad. Luzón Peña, D.M., Díaz y García Conlledo, M., y de Vicente Remesal, J., Madrid, Civitas.

RUIZ RodRíguez, L.R. (2009), «Limitaciones técnicas, jurídicas e ideológicas para el conocimiento y sanción de la criminalidad económica», Revista de Derecho penal y Criminología de la UNED, 3. ' época, enero, págs. 347-394. 
RuIz RodRíguez, L.R. (2016), «La reforma penal de los delitos contra la salud pública como respuesta a las innovaciones científicas y tecnológicas», RECPC, 18-19.

RuIz RodRíGUEz, L.R., "Las catástrofes medioambientales y la aplicación de la Ley Penal en el espacio», Revista Eguzkiloren, 2003, núm. 17, págs. 47-56.

SÁNCHez LÁZARO, F.G. (2010), «Deconstruyendo el riesgo permitido. Delitos contra la salud pública, principio de precaución, delitos contra la seguridad vial», Revista penal, núm. 25, págs. 136-150.

SchÜNEMANN, E.N. (1996), «Consideraciones críticas sobre la situación espiritual de la ciencia jurídico-penal alemana», $A D P C P$, tomo XLIX, I, págs. 187-218.

SERRANO, J.L. (2007), «Capítulo 2. La diferencia riesgo/peligro», en Red Latinoamericana y Europea sobre Gobierno de los Riesgos, Derecho, sociedad y riesgos. La sociedad contemporánea vista a partir de la idea de riesgo, Brasilia, UniCEUB, UNITAR, pág. 6586.

SIERRA AlFRANCA, I. (2001), «El concepto de raza: evolución y realidad. The breed concept: evolution and reality», Archivos de zootécnica, vol. 50, núm. 192, págs. 547-564.

Silva Días, A. (2003), «¿Y si todos lo hiciéramos? Consideraciones acerca de la «(in)capacidad de resonancia» del Derecho penal con la figura de la acumulación», $A D P C P$, tomo LVI, págs. 433 y sig.

Silva Sánchez, J.M. (1999), La expansión del Derecho penal. Aspectos de la politica criminal en las sociedades postindustriales, Madrid, Civitas.

SuÁrez GonZÁLEZ, C.J. (2003), «Derecho penal y riesgos tecnológicos», en Arroyo Zapatero, L., Neumann, U. y Nieto Martín, A. (coords.), cit., pág. 289-297.

Tanus Job e MeIra, B. (2009), La intervención del derecho penal en materia de bioseguridad. La criminalización de la actividad empresarial biotecnológica de liberación intencional en el ambiente con fines comerciales y de comercialización de productos biotech, Tesis doctoral, Universidad de Salamanca.

Terradillos Basoco, J.M. (1995), Derecho penal de la empresa, Madrid, Trotta, págs. 204-205.

Terradillos Basoco, J.M. (1992), El delito ecológico, Madrid, Trotta. 
Terradillos Basoco, J.M. (1996), «Protección penal del medioambiente en el nuevo Código penal español. Luces y sombras», Estudios penales y criminológicos, núm. 19, págs. 289-327.

Torio LóPez, A. (1983), «Cursos causales no verificables en Derecho penal», APDCP, tomo XXXVI, II, págs. 221-238.

TORIo LóPEZ, A. (1991), «Injusto penal e injusto administrativo (presupuestos para la reforma del sistema de aranceles)», en Martín-Retortillo Baquer, S., Estudios sobre la Constitución española: Homenaje al profesor Eduardo García de Enterría, vol. 3, Madrid, Civitas, págs. 2529-2546.

Zaffaroni, E.R. (1998), Tratado de Derecho penal. Parte general. Tomo I, Buenos Aires, Ediar. 
